\title{
Modelling and Forecasting Stock Returns: Exploiting the Futures Market, Regime Shifts and International Spillovers ${ }^{\infty}$
}

\author{
Lucio Sarno \\ University of Warwick \\ and \\ Giorgio Valente \\ University of Warwick \\ Centre for Economic Policy Research (CE PR)
}

This draft: November 2001

\begin{abstract}
A bstract
A large empirical literature has reported that the futures market contains valuable information for explaining stock returns and that stock returns display signi $^{-}$cant cross-correlations internationally. A parallel literature has recorded evidence that the distribution of stock returns is close to a mixture of normal distributions and that Markov switching models may therefore provide an adequate characterization of stock returns data. This paper ties together these strands of research in that we propose a vector equilibrium correction model of stock returns that exploits the information in the futures market, while also allowing for regime-switching behavior and international spillovers across stock market indices. Using data for three major stock market indices since 1988, we - nd that our model signi $i^{-}$cantly outperforms a number of alternative models in sample on the basis of standard statistical criteria. In an out-of-sample forecasting exercise, the model produces some of the highest $R^{2}$ hitherto recorded in the literature and beats all of the competing models considered on the basis of density forecast accuracy.
\end{abstract}

J EL classi- cation: G 10; G13.

K eywords: stock returns; futures; forecasting; nonlinearity; regime switching.

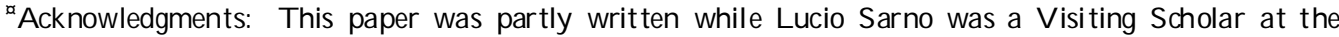
Federal R eserve Bank of St. Louis, whose hospitality is gratefully acknowl edged. Weare grateful to Abhay Abhyankar and Lutz K ilian for useful conversations and comments on previous drafts. The views expressed in the paper should not be seen as representative of the position of the Federal Reserve Bank of St. Louis or the Board of Governors of the Federal Reserve System.
} 


\section{Introduction}

A large body of both theoretical and empirical research focusing on modelling stock returns has investigated the relationship between spot and futures prices in stock index futures markets. In particular, a number of empirical studies have focused on the persistence of deviations from the cost of carry and have investigated the relationship between spot and futures prices in the context of vector autoregressions using cointegration or equilibrium correction models (see Dwyer, Locke and Yu 1996; N eely and Weller, 2000, and the references ther ein). ${ }^{1} \quad$ The rationale underlying this line of research is that the cost of carry model and variants of it predict that spot and futures prices cointegrate and their long-run relationship is characterized by a long-run equilibrium de ned by the fut ures basis, implying both mean reversion in the basis and the existence of a vect or equilibrium correction model (VECM) for spot and futures prices. ${ }^{2}$ This literature, discussed in greater detail in the next section, has generally reported evidence that the futures market contains valuable information for modelling and/ or forecasting stock returns.

A related line of research emphasizes that trading activity does not take place for one index per unit of time (e.g. see Eun and Shin, 1989; Engle and Susmel, 1994; Koutmos and Booth, 1995; Lee, 1995; K aroly and Stulz, 1996). Indeed, it is more likely that traders place orders and take positions simultaneously using di ®erent indices given that stock and fut ures markets for di ßerent indices are closely linked by both hedging activities and crossmarket arbitrage. This may generate comovements across stock market indices and, in turn, the cross-correlation between di ßerent indices may be potentially very useful in improving empirical models of stock returns. In particular, it seems possible that, in the unknown dynamic model governing the relationship between futur es and stock prices, stock returns for a particular index respond not only to the disequilibrium in the relevant stock index market but also to disequilibria in stock index markets that are linked to the relevant stock index by hedging activities and cross-market arbitrage (e.g. Ang and B ekaert, 2001; G oetzmann, $\mathrm{Li}$ and Rouwenhorst, 2001). ${ }^{3}$

A longside the work on modelling and forecasting stock prices and returns, another strand of the literature has developed where increasingly strong evidence of nonlinearities in stock price movements has been documented. One el ement of this has been the mounting evidence that the conditional distribution of stock returns is well described by a mixture of normal distributions (e.g. see Ryd nn, TerÄsvirta and A sbrink, 1998, and the references ther ein) and that, consequently, a Markov switching model may be a logical characterization of stock returns behavior (e.g. see, inter alia, LeB aron, 1992; Hamilton and Susmel, 1994; Hamilton and Lin, 1996; Ramchand and Susmel, 1998a,b; Rydęn, TerÄsvirta and § sbrink, 1998; Susmel, 1999). Also, not only Markov-switching models ${ }^{-} t$ stock returns data well, but they have often been proved to produce superior forecasts to several alternative conventional models of stock returns (e.g. see Hamilton and Susmel, 1994; Hamilton and Lin, 1996). ${ }^{4}$

In this paper, we tie together pieces of these somewhat dispar ate albeit related strands of

\footnotetext{
${ }^{1}$ R elated work as employed structural vector autoregressive models; see, for example, Lee (1998).

'Several authors have recently begun to use the term 'equilibrium correction' instead of the traditional 'error correction' as the latter term now seems to havea di Rerent meaning in some recent theories of economic forecasting (e.g. see Clements and Hendry, 1998, p. 18). Since the term 'equilibrium correction' conveys the idea of the adjustment considered in the present context quite well, we use this term below.

${ }^{3}$ For example, Ang and Bekaert (2001) ${ }^{-}$nd that cross-country predictability is stronger than predictability using local instruments. Goetzmann, Li and Rouwenhorst (2001) document the correlation structure of several major equity returns over 150 years. See also Lee (1995).

${ }^{4}$ Other studies in this literature have provided ample empirical evidence that the dynamic relationship linking stock and futures prices may be characterized by signi ${ }^{-}$cant nonlinearities that can be well char-
} 
research. In particular, we invest igate whether allowing for nonlinearities and international spillovers in the underlying data-generating process for a VECM that links spot and futures prices yields an improvement, in terms of both in-sample ${ }^{-} t$ and out-of-sample forecasting, over conventional models of stock returns that do not all ow for nonl in earities and/ or inter national spillovers. This is done through estimating a fairly general Markov-switching VECM (MS-VECM) for stock prices and futures prices that is based on an extension of M arkovian regime shifts to a nonstationary framework, for which the underlying economet ric theory has recently been developed. G iven the evidence of signi ${ }^{-}$cant regime-switching behavior in stock returns and the evidence on international cross-correlations of st ock returns discussed above, this seems a natural way to extend current econometric procedures applied to stock returns modelling and forecasting, even though this involves est imating and forecasting from a sophisticated multivariate nonlinear model.

Using weekly data since 1988 for thre major stock market indices - the S\&P 500, the NIKKEI 225 and the FTSE 100 indices - we con ${ }^{-}$rm that the futures market does contain valuable information to explain stock returns in a linear VECM framework. However, we show that conventional linear VECM s, even when allowing for international spillovers in the equilibrium correction equations, display signi ${ }^{-}$cant residual nonlinearity and are strongly rejected when tested against the alternative of an MS-VECM. Thus, we show that allowing for nonlinearities and for inter national spillovers in an MS-VECM results in a superior empirical model which explains a large proportion of the stock returns examined over the sample. Finally, we compare the performance of our proposed model to several alternative linear and nonlinear models in an out-of-sample for ecasting exercise. The evaluation of the relative performance is based on conventional statistical criteria for point forecasting performance as well as on the ability of the models to forecast the true predictive density of stock returns out of sample. ${ }^{5}$ In fact, we argue and provide evidence that density forecast accuracy is more appropriate for evaluating our competing models since stock returns are non-normally distributed and we are considering nonlinear models consistent with nonnormal densities (see, inter alia, Diebold, Gunther and Tay, 1998; Granger and Pesaran, 1999; Tay and Wallis, 2000; Timmerman, 2000). To anticipate our forecasting results, we -nd that the MS-VECM that allows for international spillovers does not outperform the competing models examined in terms of point forecasting performance, even though it generates a remarkably high $\mathrm{R}^{2}$ out of sample. However, our model signi ${ }^{-}$cantly outperforms all of the competing models in terms of density forecasting performance in that it generates predictive densities that are much closer to the true predictive density of the data.

The remainder of the paper is set out as follows. In Section 2 we describe our empirical framework for modelling stock and futures prices allowing for international spillovers and nonlinear dynamics. We also brie ${ }^{\circ} y$ set out the econometrics of Markov-switching multivariate models as applied to nonstationary processes and cointegrated systems. In Section 3 we report our empirical testing and estimation results, while in the subsequent section we report our forecasting results. A ' nal section concludes.

acterized using threshold models of various sort. These nonli nearities are rationalized on the basis of a number of di æerent factors such as non-zero transactions costs or infrequent trading or simply the existence of regime shifts in the dynamic adjustment of stock and futures price changes towards their long-run equilibrium values (e.g. see, inter alia, Yadav, Pope and Paudyal, 1994; Dwyer, Locke and Yu, 1996; Gao and Wang, 1999).

${ }^{5}$ By true predictive density of the data we mean the density of the data estimated over the chosen forecast period. Therefore, no forecast is in fact carried out in this case, and the term 'predictive' simply refers to the fact that the density in question is not estimated over the full sample but only over the forecast period. 


\section{M odelling stock returns: an empirical framework}

In this section we outline our empirical framework for modelling stock returns, which we apply to our data in the subsequent sections. F irst, we use a simple variant of the cost of carry model to show that futures and stock prices must be cointegrated and, ther efore, linked by a VECM that can be used both to explain and forecast stock returns. Second, we generalize the VECM linking stock and fut ures prices to take into account potentially import ant regime switches of the kind reported by a large empirical literature. Third, we further generalize our empirical framework by also taking into account the observed crosscorrelations between major stock market indices, which leads us to consider a system of VECM s which explicitly allows for both regime shifts and international spillovers in major stock market indices.

\subsection{The information in the futures market}

A useful starting point for building an empirical framework to model stock returns is the relationship between stock prices and stock futures prices, as described by a conventional cost of carry model with no transaction costs. Consider, for example, a market containing an asset, a stock index, whose price $\mathrm{S}(\mathrm{t})$ under the equivalent martingale measure evolves according to:

$$
d S(t)=S(t)(r ; \quad q) d t+3 / 4 d W_{S}(t) ;
$$

where $r$ is the (constant) risk-free interest rate; $q$ is the (constant) dividend yield on the index; $3 / 4$ is the volatility of the index; $W_{S}(t)$ is a one-dimensional standard Brownian motion in a complete probability space.

Standard derivatives pricing theory gives the following expression for the futures price $\mathrm{F}(\mathrm{t} ; \mathrm{T})$ at time $\mathrm{t}$ for delivery of the stock at time $\mathrm{T}, \mathrm{t}$ :

$$
F(t ; T)=E[S(T) j F(t)] ;
$$

where $E$ denotes the mathematical expectation with respect to the martingale measure $P$, and $F(t)$ denotes the information set at time $t$ (e.g. see K aratzas and Shreve, 1998). Given (1)-(2), the futures price has the well-known formula:

$$
F(t ; T)=S(t) \exp \left(r_{c}(T ; t)\right),
$$

where $r_{c}=r_{i} q$. This is the familiar expression for a futures price in a non-random interest rate environment. ${ }^{6}$

Taking logarithms of both sides of equation (3) and rearranging yields:

$$
\left[\log F(t ; T) ; r_{c}(T ; t)\right] ; \log S(t)=0 .
$$

If the logarithm of the futures price adjusted for interests and dividends and the logarithm of the stock price are both unit root or I(1) processes, then equation (4) implies that the adjusted log-futures price and the log-stock price move together. In turn, this implies

\footnotetext{
${ }^{6}$ A Iternatively, equation (3) can bederived without assuming the process for $S(t)$ given in (1), by assuming that the futures price implied by the cost of carry model is $\left.F(t ; T)=S(t)\left[\exp _{c}(T ; t)\right]\left(1_{i} \quad \# T ; t\right)\right)$. If $\sharp T ; t)$ is small, then $\left.(1 ; \sharp(T ; t)) 1 / 4 \exp _{i} \sharp T ; t\right)$ and the equation for the futures price can be approximated by equation (3) (e.g. see Dwyer, Locke and Yu, 1996).
} 
that adjusted futures and stock prices exhibit a common stochastic trend and are cointegrated with cointegrating vector $[1 ; i 1]$. In our empirical work, we subtract the weekly mean from the logarithms of the futures and stock prices. Demeaning the futures price removes the constant part of the dividends and interest rates for that week, so that the demeaned logarithms of the futures and stock prices should cointegrate with cointegrating vect or $[1 ; ; 1]$. Also, the di ßerence between the demeaned logarithms of the futures and stock prices is the deviation of the futures basis from its weekly mean. ${ }^{7}$

Further, by the $G$ ranger R epresentation Theorem (Engle and G ranger, 1987) the futures and stock prices must possess a VECM representation where the adjusted (i.e. demeaned) futures basis plays the part of the equilibrium error. We exploit this framework and use exactly a VECM representation to demonstrate that a large amount of information may be extracted from the fut ures market in order to forecast stock returns.

\subsection{Regime-switching equilibrium correction in stock index futures markets}

A large literature has documented convincing evidence of nonlinearities in stock returns. One element of this has been the mounting evidence that the conditional distribution of stock returns is well described by a mixture of normal distributions (e.g. see R yd ton, TerÄsvirta and A sbrink, 1998, and the references ther ein) and that, consequently, a M arkov switching model may be a logical characterization of stock returns behavior (e.g. see, inter alia, LeBaron, 1992; Hamilton and Susmel, 1994; Hamilton and Lin, 1996; R amchand and Susmel, 1998a,b; R yd $\AA$ n, T er ̈̈svirta and $\AA$ sbrink, 1998; Susmel, 1999). In fact, the relevant literature suggests that not only Markov-switching models ${ }^{-} t$ stock price data well, but they often perform very satisfactorily in for ecasting (e.g. see Hamilton and Susmel, 1994; Hamilton and Lin, 1996).

In the present paper, we investigat e whether allowing for regime-switching in the VECM implied by the framework described in the previous subsection yields superior stock returns forecasts relative to several alternative speci ${ }^{-}$cations. This is done through estimating a fairly general MS-VECM for stock prices and futures prices which is essentially based on an extension of Markovian regime shifts to a nonstationary framework. In the rest of this subsection we outline the econometric procedure employed in order to model regime shift s in the dynamic relationship between stock and futures prices. The procedure essentially extends Hamilton's (1988, 1989) Markov-switching regime framework to nonstationary systems, allowing us to apply it to cointegrated vector autor egressive (VAR) and VECM systems (see K rolzig, 1997, 1999, 2000).

Consider the following $M$-regime $p$-th order Markov-switching vector autoregression $(M S(M)-V A R(p))$ which allows for regime shifts in the intercept term:

$$
y_{t}=o\left(z_{t}\right)+{ }_{i=1}^{X^{p}} i i_{t_{i}} i+{ }^{\prime} \text {; }
$$

where $y_{t}$ is a $K$-dimensional observed time series vector, $y_{t}=\left[y_{1 t} ; y_{2 t} ;:: ; y_{k t}\right]^{0}, \stackrel{o}{\prime}\left(z_{t}\right)=$ $\left[{ }_{1}\left(z_{t}\right) ; \underline{o}_{2}\left(z_{t}\right) ;::: ; \underline{o}_{K}\left(z_{t}\right)\right]^{0}$ is a $K$-dimensional column vector of regime-dependent inter cept

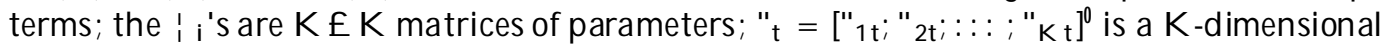
vect or of Gaussian white noise processes with covariance matrix $\S, " t » N I D(0 ; \S)$. The regimegenerating process is assumed to be an ergodic Markov chain with a ${ }^{-}$nite number of

\footnotetext{
${ }^{7}$ The logarithmic basis $b(t ; T)$ at time $t$ is de ${ }^{-} n e d$ as $\log B(t ; T)=\log F(t ; T)$ i $\log S(t)$.
} 
states $z_{t} 2 \mathrm{f} 1 ;::: ; M g$ governed by the transition probabilities $p_{i j}=\operatorname{Pr}\left(z_{t+1}=j j z_{t}=i\right)$, and ${ }_{j=1}^{M} p_{i j}=18 i ; j 2$ f $1 ;:: ; ; M$ g. ${ }^{8}$

A standard case in economics and ${ }^{-}$nance is that $y_{t}$ is nonstationary but ${ }^{-}$rst-di Berence stationary, i.e. $y_{t} \gg I(1)$. Then, given $y_{t} \gg I(1)$, there may be up to $K{ }_{i} 1$ linearly independent cointegrating relationships, which represent the long-run equilibrium of the system, and the equilibrium error (the deviation from the long-run equilibrium) is measured by the stationary stochastic process $u_{t}={ }^{B} y_{t} i^{-}$(Granger, 1986; Engle and Granger, 1987). If indeed there is cointegration, the cointegrated MS-VAR (5) implies an M S-VECM of the form:

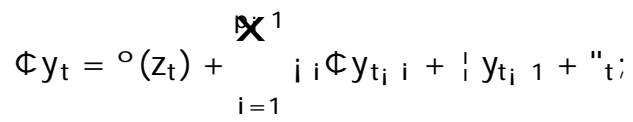

where $i_{i}=i_{j=i+1} i_{j}$ are matrices of parameters, and $l_{i=1} P_{i} i_{i} l$ is the long-run impact mat rix whose rank $r$ determines the number of coint egrating vectors (e.g. J ohansen, 1995; K rolzig, 1999) ${ }^{9}$

Although, for expositional purposes, we have outlined the MS-VECM framework for the case of regime shifts in the intercept alone, shifts may be allowed for elsewhere. The present application focuses on a multivariate model comprising, for each of the three major stock index futures markets analyzed, the futures price and the stock price (hence $y_{t}=\left[f_{t} ; s_{t}\right]$ ) where $f_{t}$ and $s_{t}$ denote the demeaned logarithmic futures and stock prices respectively. Following the reasoning of our discussion in Section 2.1, a unique coint egrating relationship should exist between $f_{t}$ and $s_{t}$. As discussed in Section 3 below, in our empirical work, after considerable experimentation, we selected a speci ${ }^{-}$cation of the MS-VECM which allows for regime shifts in the intercept as well as in the variance-covariance matrix. This model, the Markov-Switching-Intercept-H eteroskedastic-VECM or M SIH-VECM, may be written as follows:

$$
\$ y_{t}=o\left(z_{t}\right)+\sum_{i=1}^{1} i_{i} \notin y_{t_{i} i}+i y_{t_{i}}+u_{t}
$$

where $=\mathbb{R}^{-0}, u_{t} \gg N I I D\left(0 ; \S\left(z_{t}\right)\right)$ and $z_{t} 2 f 1 ;::: ; M g$.

An M S-VECM can be estimat ed using a two-stage maximum likelihood procedure. The - $r$ st stage essent ially consists of the implementation of the J ohansen $(1988,1991)$ maximum likelihood cointegration procedure in order to test for the number of cointegrating relationships in the system and to estimate the cointegration matrix. In fact, in the ${ }^{-}$rst stage use of the conventional Johansen procedure is valid without modelling the Markovian regime shifts explicitly (see Saikkonen, 1992; Saikkonen and Luukkonen, 1997). The second stage then consists of the implementation of an expectation-maximization (EM) algorithm for

\footnotetext{
${ }^{8}$ To be precise, $\mathrm{zt}$ is assumed to follow an ergodic $M$-state $M$ arkov process with transition matrix

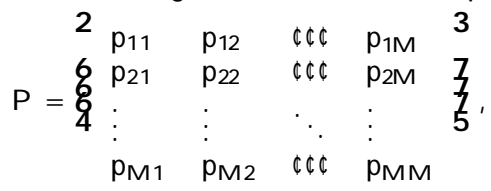

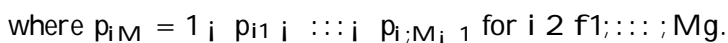

9 In this section it is assumed that $0<r<K$, implying that $y_{t}$ is neither purely di Rerence-stationary (i.e. $r=0$ ) nor is a stationary vector (i.e. $r=K$ ).
} 
maximum likelihood estimation which yields estimates of the remaining parameters of the model (Dempster, Laird and Rubin, 1977; Hamilt on, 1990; K im and Nelson, 1999; K rolzig, 1999).

\subsection{Separation and cointegration in modelling stock returns}

Although conventional time series models employed to explain or forecast stock returns treat a particular asset or index in isolation, a vast empirical and theoretical literature in - nance has pointed out that trading activity does not take place for one index per unit of time (see, inter alia, Eun and Shin, 1989; Engle and Susmel, 1994; Koutmos and Booth, 1995; Lee, 1995; K aroly and Stulz, 1996). This literature generally emphasizes that hedging activities and cross-market arbitrage may generate comovements across di ßerent stock market indices (A ng and Bekaert, 2001; Goetzmann, Li and Rouwenhorst, 2001) and, in turn, the cor relation between di ßerent indices may be potentially very useful in improving empirical models of stock returns. In particular, it is possible that, in a VECM for futures and stock prices, stock price changes respond not only to the disequilibrium in the relevant stock index market but also to disequilibria in stock index markets that are linked to the relevant stock index.

Table 1, which reports correlation coe \pm cients for the three di ßerent fut ures bases examined in this study (the S\&P 500, the FT SE 100, and the NIKKEI 225), provides clear evidence in favor of the conjecture that the three futures bases of these indices display substantial and statistically signi ${ }^{-}$cant cross-correlation, ranging from about 21 percent for the S\&P 500-NIKKEI 225 pair to about 58 percent for the NIKKEI 225-FTSE 100 pair. These correlations indicate clear interdependencies between these three major stock market indices, suggesting that the allowance for spillovers in our spot-futures VECM may yield substantial improvements relative to individual VECM estimation due to the incremental information yielded by the cross-correlation of the indices examined.

This line of reasoning suggests the possibility of enriching our MS-VECM framework by allowing for spillovers through the equilibrium correction terms, that is by allowing for the possibility that equilibrium correction terms from one coint egrating relationship for a particular stock market index may have explanatory power in the equilibrium correction equation driving the returns of another stock market index. This approach is consistent with the notion of separation and cointegration - popularized by K on ishi and Granger (1993), K onishi (1993), Granger and Swanson (1996), Granger and Haldrup (1997) - which therefore provides a useful way of describing formally the above ideas.

$f$ Consider the MS-VECM (6) and de ne an n-dimensional cointegrated vector $Y_{t}=$ $\mathrm{y}_{\mathrm{t}}^{1} ; \mathrm{y}_{\mathrm{t}}^{2} ; \mathrm{y}_{\mathrm{t}}^{300}$, where $\mathrm{y}_{\mathrm{t}}^{\mathrm{j}}=\left[\mathrm{f}_{\mathrm{t}}^{\mathrm{j}} ; \mathrm{s}_{\mathrm{t}}^{j}\right]^{0}$ for $\mathrm{j}=1 ; 2 ; 3$ is of dimension of $\mathrm{n}^{\mathrm{j}}$ (i.e. $\mathrm{n}=\mathrm{n}^{1}+\mathrm{n}^{2}+\mathrm{n}^{3}$ ) and $y_{t}^{1}, y_{t}^{2}$ and $y_{t}^{3}$ have no variable in common. We can then generalize equation (6) to a VECM that exploits the information in the futures market while also allowing for both regime shifts and international spillovers. This VECM may be written as follows:

$$
\phi Y_{t}=o\left(z_{t}\right)+{ }_{i=1}^{\mathbb{1}} w_{i} \phi Y_{t_{i} i}+\circledR^{-} q_{t_{i} 1}+{ }_{t} ;
$$

where $x_{i}$ is an $n f n$ matrix of autoregressive parameters, $®$ and ${ }^{-0}$ denote the $n f r$ loading matrix and the $\mathrm{r} \in \mathrm{n}$ cointegration matrix (or matrix of cointegrating vectors) respectively, and $r$ is the cointegration rank. The cointegration matrix ${ }^{-0}$ can be factorized as 


$$
-0=\begin{array}{ccccc}
2 & -0 & 0 & 0 & 3 \\
& 11 & -0 & 0 & 5 \\
0 & 22 & -0 & \\
0 & 0 & 33 &
\end{array}
$$

where ${ }^{-0}$ is $^{\mathrm{j}} \pm \mathrm{n}^{\mathrm{j}}$, for $\mathrm{j}=1 ; 2 ; 3$. The system is said to have separate cointegration with cointegration ranks for each subsystem given by $n^{1}, n^{2}$ and $n^{3}$ respectively. If we then factorize the loading matrix as follows

$$
\AA=4 \begin{array}{ccccc}
2 & & & & 3 \\
& \AA_{11} & 0 & 0 & \\
& 0 & \AA_{22} & 0 & 5 \\
& 0 & 0 & \AA_{33} &
\end{array}
$$

we have type B-separation or separation in the equilibrium correction, whereas if we factorize the matrix $x_{i}$ as

$$
x_{i}=4 \begin{array}{ccccc}
2 & x_{11}^{j} & 0 & 0 & 3 \\
0 & x_{22}^{j} & 0 & 5 \\
0 & 0 & x_{33}^{j} &
\end{array}
$$

we have type A-separation or separation in the dynamic adjustment towards the long-run equilibrium de ${ }^{-}$ned for each $y^{j}$ for $\mathrm{j}=1 ; 2 ; 3$ (e.g. Granger and Haldrup, 1997). If all of the conditions (9)-(11) hold there is complete separation, while if condition (9) is associated with either (10) or (11) we have partial separation.

Our earlier discussion on spillovers in the dynamics of stock market returns is consistent with a situation where, although two or more di ßerent stock indices are 'separated in the long-run' (i.e. condition (9) holds), there may be important short-run relationships between them and, therefore, the deviation from the equilibrium relationship (de- ned by the futures basis) from one index may enter the equilibrium correction equation of another index (i.e. condition (11) does not hold).

This 'amalgamation' is applied to the case of cointegration analysis across di ßerent stock indices in the world economy, which seems intuitively appealing given the high degree of integration of global capital markets during the last ${ }^{-}$fteen years or so. In particular, our framework is consistent with a situation where, for any stock index k, a long-run equilibrium relationship is established in a static cointegrating equation involving the stock and futures prices for index k, as predicted by the standard cost of carry model. Hence, stock and fut ures prices for any other index j $\sigma \mathrm{k}$ do not enter the long-run cointegration equation $\mathrm{de}^{-}$ning the equilibrium value of the stock price of index $k$. Despite long-run separation (that is the equilibrium value of the stock price of any index $k$ is fully determined by the equilibrium relationship between stock and futures prices of the index $k$ itself), however, the individual short-run relationships may be characterized by the equilibrium error from one equation entering another equilibrium correction equation of the system. This is the approach followed below, where we start by estimating cointegrating relationships and, ther efore, equilibrium correction terms, which imply plausible parameters and are consistent with the de $e^{-}$nition of the fut ures basis (i.e. with the $[1 ; i 1]$ cointegrating vector implied by the framework in Section 2.1). Thus, we estimate a nonlinear MS-VECM where, for each stock index examined, the lagged deviation from equilibrium (equilibrium correction term) 
in other stock indices is allowed to enter the equilibrium correction equation in addition to the own-index lagged deviation from equilibrium (equilibrium correction term) in order to exploit the information content of international spillovers.

\section{Empirical analysis I: modelling}

\subsection{Data, preliminary statistics and cointegration analysis}

The data set comprises weekly time series on futures written on the S\&P 500, the NIK KEI 225 and the FT SE 100 indices, as well as price levels of the corresponding underlying cash indices. The data were obtained from Datastream, and the sample period examined spans from September 1988 to December 2000. We use this sample period because the NIK KEI 225 st ock index fut ures was ${ }^{-}$rst traded on September 31988 in the Osaka St ock Exchange (OSE ). ${ }^{10}$ In our empirical work, we carried out estimations over the period September 1988December 1998, reserving the last two years of dat a for out-of-sample forecasting tests.

Panel A of Table 2 provides summary statistics of the logarithm of the futures price, $f_{t}$ and the logarithm of the spot price, $s_{t}$. As one would expect, for each stock index, the ${ }^{-}$rst moment of the futures price is larger than the ${ }^{-}$rst moment of the spot price (although it is not the case that $f_{t}>s_{t}$ at each point in time), while the second moment of the spot price is larger than the second moment of the futures price, suggesting that the futures price is larger on average and less volatile than the spot price. The partial autocorrelation functions, reported in Table 2 up to order 12, suggest that each spot and fut ures price examined displays very strong ${ }^{-}$rst-order serial correlation, while none of these series ap pears to be signi ${ }^{-}$cantly serially correlated at higher lags. ${ }^{11}$

As a preliminary exercise, we tested for unit root behavior of each of the $(\log )$ futures price and spot price time series by calculating standard augmented Dickey-Fuller test stat istics. ${ }^{12}$ In each case, the number of lags was chosen such that no residual autocor relation was evident in the auxiliary regressions. In keeping with the very large number of studies of unit root behavior for these time series and conventional ' nance theory, we were in each case unable to reject the unit root null hypothesis at conventional nominal levels of signi' cance. On the other hand, di Ber encing the series did appear to induce stationarity in each case. Overall, the unit root tests clearly indicate that both $f_{t}$ and $s_{t}$ are realizations from stochastic processes integrated of order one, which suggests that testing for cointegration between $f_{t}$ and $s_{t}$ is the logical next step.

The implementation of the J ohansen (1988, 1991) maximum likelihood cointegration procedure is essentially the ${ }^{-}$rst stage of the two-stage procedure designed to estimate an

\footnotetext{
${ }^{10} \mathrm{M}$ ore precisely, NIKKEI 225 futures contracts were ${ }^{-}$rst traded in 1986 in the Singapore International Monetary Exchange (SIMEX). Since NIKKEI 225 futures contracts are more actively traded in the OSE than the SIMEX we prefer to use the OSE data (see Pan and Hsueh, 1998, for further discussion of the institutional details of trading the NIKKEI 225 stodk index futures contracts).

${ }^{11}$ Considering that some of the papers in a related literature were engendered by considerations of microctructural nature and focused on price and basis changes (e.g. Miller, Muthuswamy and Whaley, 1994), we al so examined the autocorrelation function (up to 12 lags) of spot price changes, futures price changes, and basis changes for all indices studied. The results (not reported to conserve space but available upon request) indicated that changes in both spot and futures prices for each index display signi ${ }^{-}$cant autocorrelation, fairly strong especially at lag 1 . Further, for each index, changes in the futures basis display the well-documented negative autocorrelation. As suggested by Miller, Muthuswamy and Whaley (1994), the negative autocorrelation of the basis has important i mplications for microstructural "nance, and - at least at high frequency - may be generated by the fact that index stocks do not trade continuously.

${ }^{12}$ The results are not reported to save space, but they are avai lable from the authors upon request.
} 
MS-VECM for $\phi f_{t}$ and $\phi S_{t}$, as discussed in Section 2.2. We employed the Johansen procedure in a VAR allowing for a maximum lag length of ${ }^{-}$ve and an unrest rict ed constant term, hence testing for cointegration in the long-run model: ${ }^{13}$

$$
\mathrm{f}_{\mathrm{t}} \mathrm{i} \quad \mathrm{As}_{\mathrm{t}}=\# \text {. }
$$

Both J ohansen likelihood ratio ( $L R$ ) test statistics (based on the maximum eigenvalue and on the trace of the stochastic matrix respectively) clearly suggested that a cointegrating relationship existed. A Iso, the restriction suggested by framework described in Section 2.1 that the cointegrating parameter associated with st equals unity $(\hat{A}=1)$ could not be rejected at conventional nominal levels of signi ${ }^{-}$cance for each of the estimated VARs. ${ }^{14}$ Given the restriction $\dot{A}=1$, the cointegrating residuals may be sen as the estimated deviation of the basis from its mean.

Overall, the results in this section suggest that a unique cointegrating relationship exists between $\mathrm{ft}_{\mathrm{t}}$ and $\mathrm{st}$ for each of the three major stock indices examined, lending support to the simple framework outlined in Section 2.1.

\subsection{Linear dynamic modelling and linearity tests}

Preliminary to considering an M S-VECM, we estimated a standard linear bivariate VECM for $\phi f_{t}$ and $\phi s_{t}$, which is implied by the ${ }^{-}$nding of cointegration between $f_{t}$ and $s_{t}$ reported in the previous sub-section ( $\mathrm{G}$ ranger, 1986; Engle and G ranger, 1987). Thus, using fullinformation maximum likelihood (FIML) methods, we estimated for each stock index a bivariate VECM of the form

$$
\phi y_{t}=0+\gtrless_{i=1}^{1} x_{i} \phi y_{t_{i} i}+i y_{t_{i} 1}+{ }^{\prime} t
$$

where $y_{t}=\left[f_{t} ; S_{t}\right]^{0}$, we allowed for a maximum lag length of ${ }^{-}$ve as suggested by both the A kaike information criterion (AIC) and the Schwartz information criterion (SIC). E mploying the conventional general-to-speci ${ }^{-} \mathrm{c}$ procedure, we obtained, for each stock index examined, fairly parsimonious models for $\$ f_{t}$ and $\$ s_{t}$ which display no residual serial correlation. ${ }^{15}$

Further, in order to test for cointegration and separation of the type discussed in Section 2.3, we estimat ed the following model:

$$
\phi Y_{t}=0+\sum_{i=1}^{1} w_{i} \notin Y_{t_{i} i}+i Y_{t_{i} 1}+"{ }_{t}
$$

\footnotetext{
${ }^{13}$ The VAR considered is essentially mode $H_{1}^{\alpha}(r)$ in J ohansen (1995, p. 83) notation, where a linear deterministic trend is i mpli citly allowed for but this can be eliminated by the cointegrating relations and the process contains no trend-stationary components; hence, the model allows for a linear trend in each variable but not in the cointegrating relations.

${ }^{14} \mathrm{LR}$ tests of the hypothesis $\mathrm{A}=1$ could not be rejected with $p$-values equal to $0.616,0.587$ and 0.603 for the S\&P 500, the NIKKEI 225 and the FTSE 100 respectively.

${ }^{15} \mathrm{Full}$ details on these estimation resul ts are available from the authors upon request, but are not reported to conserve space and because the main focus of this section of the paper is on linearity testing appl ied to the linear VECM residual s.
} 
where $Y_{t}=\left[f_{t}^{\text {SP 500 }} ; s_{t}^{S P 500} ; f_{t}^{N ~ K 225} ; s_{t}^{N ~ K 225} ; f_{t}^{F ~ T S E ~ 100 ; ~} s_{t}^{F T S E ~ 100 ~}\right]$. W e tested for type Bseparation (separation in the equilibrium correction) by estimating model (14) imposing the zero restrictions as in (10) and executing a standard likelihood ratio (LR) test. The results allow us to reject the zero restrictions under the null hypothesis (10), implying that there is no separation in the equilibrium correction, or put di ßerently, that the disequilibrium (deviation of the basis from its equilibrium level) in one index in ${ }^{\circ}$ uences the dynamics of stock returns of other indices.

A s a check of adequateness of the models as well as an additional motivation for the need of employing a nonlinear model to characterize the dynamic relationship between stock and futures prices, however, we employed two fairly general tests for linearity of the residuals from the VECMs (13) and (14), namely Ramsey's (1969) RESET test and the B rock, Dechert and Sheinkman (BDS) (1991) test for testing the null hypothesis that the residuals from (13) and (14) are independent and identically distributed (iid) against an unspeci- ed alternative. $^{16}$ Application of both of these tests provided strong empirical evidence that the linear VECM fails to capture important nonlinearities in the data generating process, as linearity is rejected with marginal signi ${ }^{-}$cance levels ( $p$-values) of virtually zero (see Panels a) and b) of Table 4). ${ }^{17}$

\subsection{S-VECM estimation results}

Next, we applied the conventional \bottom-up" procedure designed to detect M arkovian shifts in order to select the most adequate characterization of an $\mathrm{M}$-regime $\mathrm{p}$-th order MS-VECM for $\$ y_{t}$ of the form discussed in Section 2.18 However, for any MS-VECM estimated the implicit assumption that the regime shifts a ßect only the drift term of the VECM was found to be inappropriate. In fact, we checked the relevance of conditional heter oskedasticity by estimating an M S-VECM where the Gaussian innovation is al lowed to be heteroskedastic, "t $\gg N I D\left(0 ; \S\left(z_{t}\right)\right)$. We then tested the hypothesis of no regime dependence in the variance-covariance matrix using an LR test of the type suggested by Krolzig (1997, p. 136). The results suggest very strong rejection of the null of no regime dependence, clearly indicating that an M S-VECM that allows for shifts in both the inter cept v and

\footnotetext{
${ }_{16}$ Under the RESET test statistic, the alternative model involves a higher-order polynomial to represent a di Rerent functional form; under the null hypothesis, the statistic is distributed as $\hat{A}^{2}(q)$ with q equal to the number of higher-order terms in the alternative model. The BDS test for a series ut is cal culated in the following way. Let $u_{t ; v}$ be a set of consecutive terms from $u_{t}: u_{t ; v} f u_{t} ; u_{t+1} ;::: ; u_{t+v_{i}} g$. The pair of vectors $u_{t ; v}$ and $u_{s ; v}$ are said to be no more than \& apart if $j u_{t+j} i u_{s+j} j . \&$ for $j=0 ; 1 ;:: ; ; v i$. Thus, the correlation integral $C_{V}(\&)$ is de ned as the product of the limit of $T^{-}{ }^{2} 2$ ( $T$ being the number of observations) times the number of \& close pairs $(s ; t)$, essentially measuring the probability that the pai rs of points $(\mathrm{s} ; \mathrm{t})$ are within \&of each other. The BDS statistic is then constructed as $\mathrm{S}(\mathrm{v} ; \&)=\mathscr{\bigotimes}_{\mathrm{v}}\left(\otimes_{\mathrm{i}}\left[\mathscr{\bigotimes}_{1}(\&]^{\mathrm{v}}\right.\right.$ for some $v$ and \& Under the null hypothesis that $u_{t}$ is iid, $\bar{T}[S(v ; \&] » N(0 ; »)$, where the vari ance » is a function of $v$ and $\&$ Rejection of the null implies that some form of nonlinearity is present in $u_{t}$, although the type of nonlinearity cannot be exactly determined under the BDS test. BDS (1991) suggest that the choice of $\mathrm{v}$ and, particularly, the choice of $\&$ are crucial for the power of the test, which is reasonably powerful only in large samples. BDS (1991) also suggest values of \& between 0.5 and 1.5 times the standard deviation of $u_{t}$, whereas the value of $v$ should preferably be such that $(T \Rightarrow v)>200$.

${ }^{17}$ However, we also used the linear VECM s to forecast the future stock price and compared these forecasts to the forecasts obtai ned from estimating an MS-VECM, as discussed below.

${ }^{18}$ Essentially the bottom-up procedure consists of starting with a simple but statistical ly reliable Markov switching model by restricting the eRects of regime shifts on a limited number of parameters and check the model agai nst alternati ves. In such a procedure, most of the structure contained in the data is not attributed to regimeshifts, but explained by observable variables, ther efore being consistent with the general-to-speci ${ }^{-} \mathrm{c}$ approach to econometric modelling. For a comprehensive discussion of the bottom-up procedure, see Krolzig (1997).
} 
the variance-covariance matrix $\S$, that is an MSIH(M )-VECM (p), is the most appropriate model within its class in the present application. Then, we tested for the signi ${ }^{-}$cance of the autoregressive structure and found that $p=1$ is the lag length which better characterizes the dynamics of the series. ${ }^{19}$ For simplicity, we assume, as done in much recent literat ure on Markov-switching models (see, inter alia, Cecchetti, Pok-Sang and Mark, 1990, 2000; Hamilton and Lin, 1996; Richmond and Susmel, 1998a,b), the presence of two regimes for each stock index.

Thus, we selected and estimated a bivariate MSIH(2)-VECM (1) for $\$ y_{t}$ of the form

$$
\begin{gathered}
\Phi y_{t}=o\left(z_{t}\right)+\sum_{i=1}^{1} x_{i} \phi y_{t_{i} i}+i y_{t_{i} 1}+" t \\
{ }_{t} \gg N I D\left(0 ; \S\left(z_{t}\right)\right) \quad z_{t}=1 ; 2
\end{gathered}
$$

using the EM algorithm for maximum likelihood estimation discussed in Section 2. In or der to test for cointegration and type B-separation we also estimated the following model

$$
\begin{gathered}
\phi Y_{t}=0\left(z_{t}\right)+\sum_{i=1}^{1} \alpha_{i} \phi Y_{t_{i} i}+Y_{t_{i} 1}+"{ }_{t} \\
t_{t} \gg N I D\left(0 ; \S\left(z_{t}\right)\right) \quad z_{t}=1 ; 2:
\end{gathered}
$$

Making no assumption on the relationship between the regime shifts occurring in the stock in dices examined (see K rolzig, 1997; Hamilton and L in, 1996) implies that the number of regimes incorporated in model (16), and consequently the dimension of the transition matrix, is $2^{3}=8^{20}$

The empirical results are very encouraging on a number of fronts. The estimation yields plausible results for each VECM estimated, with all coe \pm cients found to be strongly statistically signi $i^{-}$cantly di ßerent from zero at conventional levels of signi $i^{-}$cance. $^{21}$ The impact eßect of regime shifts al so appears to be substantial on the variance-covariance matrix $\S\left(z_{t}\right)$. Furthermore, we computed an LR test statistic for linearity, which essentially tests the hypothesis that the true model is a linear VECM against the alternative of the MSIHVECM reported in Table 5. Even by invoking the upper bound of Davies $(1977,1987)$, the linearity hypothesis is rejected very strongly, with a $p$-value of virtually zero, providing convincing evidence of the need of employing a regime-switching model that allows for shifts in $v$ and $\S$ in the econometric modelling of the data under examination. ${ }^{22}$ M oreover, even in the context of $\mathrm{M}$ arkov-switching models, type B -separation is rejected by the data. In

\footnotetext{
${ }^{19}$ One may argue that the lag length of unity which was selected by the bottom-up procedure may be too low, given that we allowed for a maximum lag length of ${ }^{-}$ve in estimating the linear VECM. Nevertheless, estimati on of an MSIH-VECM with higher-order lags provided several insigni ${ }^{-}$cant autoregressiveparameters and did not change qual itatively any of theresul ts reported below. Further, given that the diagnostic tests and the graphs of the residuals from the MSIH(3)-VECM(1) did not indicate either misspeci ${ }^{-}$cation or residual serial correlation and that the coe \pm cients of determination were found to be very high, we decided to stick to the more parsi monious models.

${ }^{20} \mathrm{~F}$ or further technical details see Appendix A.

${ }^{21}$ The full set of estimated coet cients are not reported here to save space, but full details are available upon request.

${ }^{22}$ Note that the regularity conditions under which the Davies $(1977,1987)$ test is valid may be violated, since the Markov model has both a problem of nuisance parameters and a problem of 'zero score' under the null hypothesis. Moreover, even if the Davies bound is appropriate, it is possible that it will only be
} 
fact the likelihood ratio test (LR 2) reported in the second column of Table 5 strongly rejects the null of separation in the equilibrium correction terms.

We also compute coe \pm cients of determination $\left(R^{2}\right.$ and $\left.\bar{R}^{2}\right)$; the $\bar{R}^{2}$ was adjusted both for the bias towards preferring a larger model relative to a smaller one as well as for the fact that the model allows for regime-dependent heteroskedasticity. The results are reported in Panel a) of Table 6 . Under this measure of goodness of ${ }^{-} t$, two facts arise. First, the role of non-separation in the equilibrium correction terms is important to explain the variability of futures and spot returns: columns 2 and 4 highlight the improvement in the in-sample predictive performance of the models when the futures bases from di Berent stock markets are incorporat ed as explanatory variables in the returns equations. Second, the role of nonlinearities appears to be very important to better explain stock returns. Columns 3 and 4 show how nonlinearities of the type speci ${ }^{-}$ed in Section 2 help to capture the general features exhibited by the time series under investigation. Thus, examining the last column of Panel a) of Table 6 , where international spillovers and nonlinearities are both explicitly taken into account, suggests that the in-sample performance of the model is highly satisfactory. The uncor rected $\mathrm{R}^{2}$ exhibits values larger than $45 \%$ for all futures and spot indices. Even correcting for the large number of parameters of the $\mathrm{MSIH}$ (8) VECM (1) model, the coe \pm cient of determination is at least twice as large as the coe \pm cient of determination obtained for the bivariate MS-VECM models and more than 10 times larger than the coe \pm cient of determination of the standard linear VECM models. ${ }^{23} 24$

\section{Empirical analysis II: forecasting}

\section{1 $\mathrm{R}^{2}$ out of sample and point forecasting performance}

One of our results, corroborating some previous ${ }^{-}$ndings in the relevant literature, is that futures prices contain valuable information that can be exploited to explain a sizable proportion of stock prices and returns, at least in sample. In order to better evaluate the usefulness of our nonlinear MS-VECM characterization and the gain from using a sophisticated nonlinear empirical model, dynamic out-of-sample forecasts of stock returns were constructed using the MSIH-VECM estimated and discussed in the previous section. In particular, we calculated one-step-ahead forecasts over the period J anuary 1999-December $2000 .^{25}$ The out-of-sample for ecasts for a given horizon are const ructed according to a recursive procedure that is conditional only upon information available up to the date of the

valid if thenull model is a linear model with iid errors; in the present case, it is di \pm cult to believe that this condition is met since innovations are not homoskedastic, which would induce some distortion. Therefore, the distributi on of the LR test may di ßer from the adjusted $\hat{A}^{2}$ distribution proposed by Davies $(1977,1987)$. For extensive di scussions of the problems related to LR testing in thi scontext, see Hansen $(1992,1996)$ and Garcia (1998). We are thankful to Bruce Hansen for clarifying several econometric issues related to LR testing in the present context.

${ }^{23}$ Note that all of our estimated MS-VECMs are clearly stationary, as con ${ }^{-}$rmed by calculating the value of the spectral radius as in Karlsen (1990).

${ }^{24} \mathrm{~A}$ s a way to evaluate thedynamic properties of the estimated $\mathrm{M}$ arkov-switching models we al so examined thee ${ }^{\circledR e c t s}$ of shocks on theevoluti on of the time series under investigation using generalized impulse response functions cal culated using Monte Carl o integration methods ( see Gallant, Rossi and Tauchen, 1993; K oop, Pesaran and Potter, 1996). The impulse response functions (not reported to conserve space but available upon request) show that, as expected, shocks hitting each of the three stock returns examined exhibit low persistence, dissipating over a very short time horizon.

${ }^{25} \mathrm{~F}$ or a description of the econometric issues rel ated to out-of-sample forecasting in a Markov-switching framework, see Hamilton (1993) and K rolzig (2000). 
forecasts and with successive re-estimation as the date on which forecasts are conditioned moves through the data set.

It is well know $n$ in the liter ature that forecasting with nonlinear models is in general much more di \pm cult than forecasting with linear models because of the need to condition on the distribution of future exogen ous shocks whose conditional expectation may be zero in a linear framework but not in a nonlinear framework. However, given that we compute onestepahead forecasts, the procedure often suggest ed in the literature that involves implementing numerical integration using $M$ onte $C$ arlo methods is not required as the one-step-ahead forecasts can be calculated analytically (see, inter alia, B rown and Mariano, 1984, 1989; Granger and TerÄsvirta, 1993, chapter 8; Franses and van Dijk, 2000, chapters 3-4; K rolzig, 2000).

Forecast accuracy is evaluated using several di ßerent criteria. Panel a) of Table 7 shows the $R^{2}$ out-of-sample, the mean absolute errors (MAE) and the mean square errors (MSE) for each of the estimated models. The pattern described by the $\mathrm{R}^{2}$ is encouraging. The MSIH-VECM (16) (i.e. the nonlinear VECM which allows for international spillovers) exhibits the highest goodness of ${ }^{-} t$ out-of-sample for each of the indices examined: the $R^{2}$ out-of-sample is al ways higher than 10 percent and is close to $20 \%$ in the case of the NIK KEI 225 index. Also, the di Berence between the $R^{2}$ out-of-sample from the M SIH-VECM and the $\mathrm{R}^{2}$ out-of-sample obtained from each of the alternative models is large, suggest ing that both nonl inear ities and spillovers are important to explain, even out-of-sample, the dynamics of stock returns.

This scenario is not con $^{-}$rmed, however, by the analysis of the MAE s and MSEs. Indeed, on the basis of these criteria, the M SIH-VECM (16) is slightly better (produces lower MAEs and MSEs) only for the S\&P 500 index, while for the other two stock indices examined it performs slightly worse than the alternative models. However, the results of the Diebold and Mariano (1995) test, reported in the $\mathrm{P}$ ane $\mathrm{b}$ ) of Table 7, indicate that we are not able to reject the null of equal predictive accuracy in each case. Hence the di ßerences in terms of MAES and MSEs reported in Table 7 are not statistically signi ${ }^{-}$cant. ${ }^{26} 27$

Overall, the results from analyzing the $\mathrm{R}^{2}$ out of sample, which favor the M SIH-VECM (16), appear to $\operatorname{con}^{\circ}$ ict with the results from analyzing MAEs and MSEs, which do not support any particular model.

\subsection{Density forecasting performance}

The ${ }^{-}$ndings in the previous subsection deserve further discussion. The estimated linear and nonlinear models produced a series of dynamic out-of-sample forecasts. U sing di ßerent

\footnotetext{
${ }^{26} \mathrm{~A}$ consistent estimate of the spectral density at frequency zero $\mathrm{f}_{(}(0)$ is obtained using the method of Newey and West (1987) where the optimal truncation lag has been selected using the Andrews's (1991) AR (1) rule. The rule is implemented as follows: we estimated an $A R(1)$ model to the quantity $d_{t}$ obtaining the autocorrelation coe \pm cient $b_{2}$ and the innovation variance from the $A R(1)$ process $B z$ : T hen the optimal truncation lag A for the Parzen window in the Newey and West estimator is given by the Andrews' rule $A=2: 6614 \quad B(2) T^{1=5}$ where $B(2)$ is a function of $B / 2$ and 3 . The Parzen window has been chosen according to Gallant (1987, p. 534).

${ }^{27}$ Note that the nite sample distribution of the DM statistics may deviate from normality; this problem is particularly severewhen one takes into account parameters uncertainty ( see West 1996, West and McCracken 1998; McCracken 2000). The DM statistics reported in this paper were calculated by bootstrap (see Kilian, 1999). Also, note that the non-rejection of the null of equal point forecast accuracy may bedueto the well documented low power of the Diebold-Mariano test statistic in " nite sample (see K ilian and Taylor, 2001, and the references therein).
} 
criteria to evaluate their predictive accuracy we obtained somewhat con ${ }^{\circ}$ icting results. How can one reconcile, for example, the ${ }^{-}$nding of an $\mathrm{R}^{2}$ out-of-sample lar ger than $12 \%$ or so and average improvements ranging between 5 and 12 times relative to the alternative models with our inability to beat the alternative models on the basis of MAEs and MSEs?

One possible explanation of these - ndings is suggested by careful examination of Table 8, which reports the absolute di ßerences betwen the ${ }^{-}$rst four moments of the estimated forecast densities and the true predictive density of the data. The ${ }^{-}$gures in Table 8 suggest that focusing only on the ${ }^{-}$rst two moments of the stock returns distributions, which is eßectively what one does when using point forecast accuracy tests, we do not exploit the whole information provided by the MS-VECM s out-of-sample predictions. In particular, the MSIH-VECM (16) appears to exhib it the best performance across the models considered in terms of 'closeness' of the predicted moments to the true moments of stock returns data over the forecast period, although this might not be clear if one considers only the ${ }^{-}$rst two moments of the distribution of stock returns. Th is evidence is made visually clear by F igures 1-3, which plot, for each of the stock indices examined, the forecast densities implied by each of the competing models together with the true predictive density of stock returns. The graphs make simply too apparent how the MSIH-VECM (16) produces density forecasts much closer to the true predictive density of the data than any of the other competing models. In some sense, therefore, inspection of the absolute di ®erences given in Table 8 and the forecast densities plotted in Figures 1-3 may help us to reconcile the puzzling evidence of the high $\mathrm{R}^{2}$ out-of-sample and the unsatisfactory results in terms of MAEs and MSEs documented in the previous subsection.

A logical next step then involves testing for mally the hypothesis that the forecast density implied by the MSIH-VECM ( 16) is the closest to the true predictive density of the data in order to add econometric precision to the informal evidence provided by Table 8 and Figures 1-3. A large body of literature in "nancial econometrics has recently focused on evaluating the forecast accuracy of empirical models on the basis of density, as opposed to point, forecasting performance (see, inter alia, Diebold, Gunther and Tay, 1998; Diebold, Hahn and Tay, 1999; Granger and Pesaran, 1999; T ay and W allis, 2000; T immerman, 2000; Pesaran and Skouras, 2001). Several researchers have proposed methods for evaluating density forecasts. For example, Diebold, G unther and Tay (1998) extend previous work on the probability integral transform and show how it is possible to evaluate a model-based predictive density and to test formally the hypothesis that the predictive density implied by a particular model corresponds to the true predictive density. In general, this line of research has produced several methods either to measure the closeness of two density functions or to test the hypothesis that the predictive density generated by a particular model corresponds to the true predictive density. However, these tests do not allow us to test the null hypothesis of equal density forecast accuracy between competing models.

In order to test formally the null hypothesis of equal density forecast accuracy between the MS-VECM (16) and each of the alternative models considered we employed the '-test recently proposed by Sarno and Valente (2001) for evaluating the accuracy of the density forecasts generated by com peting models. The '-test is similar in spirit to the test suggested by Diebold and M ariano (1995) but involves the analysis of the whole forecast density instead of point forecasts. ${ }^{28}$ The '-test statistic is constructed as follows:

\footnotetext{
${ }^{28}$ See A ppendix $B$ for details on the calculation and the properties of the '-test.
} 


$$
=\frac{\bar{d}}{\frac{B_{3}}{B}}
$$

where $\bar{d}=\frac{1}{B} P_{j=1}^{P} d^{j}=\frac{1}{B} P_{j=1}^{P}\left|{ }_{j}^{3} D_{1}^{j} i\right| S_{D_{2}^{j}}^{j}$ is an average (over $j=1 ; \ldots ; ; B$ bootstrap replications) of the dißerence betwen two estimated integrated square dißerences, $\mid{ }_{\infty} \$ D_{1}^{j}$ and $I \$ D_{2}^{j} ; \mid S D_{1}^{j}$ refers to the integrated square di ßerence between the MSIH-VECM (16) and the true predictive density, whereas $1 \$ D_{2}^{j}$ refers to the integrated square di ßerence between the particular competing model considered and the true predictive density; Brais a consistent bootstrap estimate of the variance of the di ßerence d. ${ }^{29}$ Under general conditions, the '-test statistic is distributed as standard normal under the null hypothesis that the two competing models have equal density forecast accuracy.

The results from applying the '-test to our models, reported in Table 9, con $^{-} \mathrm{rm}$ the informal evidence documented in Table 8 and Figures 1-3 since the null of equal density forecast accuracy is strongly rejected in each case. More precisely, for each alternative model and each stock index examined, the MSIH-VECM (16) produces the best density forecasts, with the null hypothesis of equal density forecast accuracy being rejected with p-values of virtually zero.

Summing up, the forecasting results in this section suggest that the general M SIH-VECM that allows for international spillovers performs signi ${ }^{-}$cantly better than any other linear and nonlinear model considered in this paper in terms of explaining the out of sample behavior of stock returns. In particular, while the forecasting performance of the general M SIH-VECM is not statistically di ßerent from the performance of the alternative models in terms of point forecasting, the MSIH-VECM is superior when one evaluates out-of-sample performance on the basis of the ability of the model to match the full out-of-sample predictive density of stock returns.

\section{Conclusion}

This article has re-examined the dynamic relationship between spot and futures prices in stock index futures markets using data since 1988 at weekly frequency for three major stock market indices - the S\&P 500, the NIK KEI 225 and the FT SE 100 indices. In particular, motivat ed by several related strands of research, we proposed a nonlinear, M arkov-switching vector equilibrium correction model that explicitly takes into account the large amount of evidence that the conditional distribution of stock returns is well characterized by a mixt ure of normal distributions. Also, we used the recently developed notion of 'separation and cointegration' to provide a richer characterization of the dynamics of stock returns that explicitly allows for international spillovers across these stock index and stock index futures markets.

The empirical results provide strong evidence in favor of the existence of strong international spillovers across these maj or stock markets and a well-de-ned long-run equilibrium relationship between spot and futures prices which is consistent with mean reversion in

\footnotetext{
${ }^{29}$ The estimated integrated square di ßerence 1 \$\$ $D={ }^{R}{ }^{h} R(x) ; B(x)^{i_{2}} d x$ is obtai ned by estimating the density functions $A$ and ${ }^{\circ}$ by means of the Gaussian kernel estimator.
} 
the fut ures basis and the fundamental predictions of the cost of carry model. Linear vect or equilibrium cor rection models were rejected when tested against a M arkov-switching vect or equilibrium correction model which allows for shifts in the intercept and the variancecovariance mat rix, suggest ing the need for a nonlinear, regime-switching speci ${ }^{-}$cation. Our prefer red nonlinear speci ${ }^{-}$cation explains a very large fraction of the stock returns examined, with the $\mathrm{R}^{2}$ ranging from 0.45 for the FTSE 100 index returns to 0.65 for the S\&P 500 index returns, and with the $\overline{\mathrm{R}}^{2}$ ranging from 0.18 for the NIKK EI 225 index returns to 0.26 for the S\&P 500 index returns.

Using the estimated models in an out-of-sam ple for ecasting exercise we found that both nonlinearity and international spillovers are important in forecasting future stock returns. However, their importance is not apparent when the forecasting ability of our proposed nonlinear VECM is evaluated on the basis of conventional point forecasting criteria. In fact, these criteria neglect the fact that stock returns are non-normally distributed and that the nonlinear models employed in this paper imply non-normal predictive densities. In order to adequately measure the for ecasting ability of our nonlinear model we employed a test of the null hypothesis of equal density forecast accuracy, which revealed that the forecast density implied by our preferred speci cation is, for each stock index considered, signi $^{-}$cantly closer to the true predictive density of the data than the forecast densities generated by each of the several competing models.

W hile these results aid the profession's understanding of the behavior of stock returns, we view our model as a tentatively adequate characterization of the data which appears to be superior to linear equilibrium correction modeling in a number of respects, but which nevertheless may be capable of improvement. In particular, while the model used here is very general and ${ }^{\circ}$ exible, the evidence we document suggests that global stock index and stock index futures markets are characterized by very complex dynamic interactions. Much more work needs to be done to understand these relationships. These challenges remain on the agenda for future research. 
Table 1. Correlation matrix among futures bases

\begin{tabular}{|c|c|c|c|}
\hline & $S \& P 500$ & NIKKEI 225 & FT SE 100 \\
\hline$S \& P 500$ & $\begin{array}{c}1 \\
{[i]}\end{array}$ & & \\
\hline NIK KEI 225 & $f \underset{1: 85 f 10^{i} 3^{x}}{0.21046}$ & $\begin{array}{c}1 \\
{[\mathrm{i}]}\end{array}$ & \\
\hline FTSE 100 & $f_{1: 95 £ 10^{i} 3^{a x}}^{0.39323}$ & $f_{1: 15 \mp 10^{i} 3^{x}}^{0.58048}$ & $\begin{array}{c}1 \\
{[i]}\end{array}$ \\
\hline
\end{tabular}

N otes: Estimated total correlation and st andard er rors (in brackets) are reported. St andard errors of the estimated correlation coe \pm cients are calculated by bootstrap. Data are resampled with replacement 5,000 times.

Table 2. P reliminary data statistics

\begin{tabular}{|c|c|c|c|c|c|c|}
\hline & $S \& P \quad 500: f_{t}$ & S\&P 500: $S_{t}$ & NIK KEI 225: $f_{t}$ & NIK KEI 225: $\mathrm{S}_{\mathrm{t}}$ & FTSE 100: $f_{t}$ & FTSE 100: $\mathrm{S}_{\mathrm{t}}$ \\
\hline Minimum & 5.5084 & 5.5081 & 4.1095 & 4.1099 & 7.4325 & 7.4458 \\
\hline Maximum & 6.8977 & 6.8835 & 4.5967 & 4.5901 & 8.5864 & 8.5725 \\
\hline M ean & 6.0969 & 6.0921 & 4.3122 & 4.3103 & 7.9467 & 7.9387 \\
\hline $\begin{array}{l}\text { Std Dev } \\
\text { PACF : }\end{array}$ & 0.1171 & 0.1172 & 0.1081 & 0.1098 & 0.0764 & 0.0777 \\
\hline $\operatorname{lag} 1$ & 0.9915 & 0.9917 & 0.9897 & 0.9899 & 0.9904 & 0.9912 \\
\hline $\operatorname{lag} 2$ & -0.0134 & -0.0146 & 0.0122 & 0.0104 & -0.0227 & -0.0381 \\
\hline $\operatorname{lag} 3$ & -0.0388 & -0.0368 & -0.0246 & -0.0130 & -0.0182 & -0.0202 \\
\hline $\operatorname{lag} 4$ & -0.0105 & -0.0117 & 0.0114 & -0.0225 & 0.0158 & 0.0159 \\
\hline $\operatorname{lag} 5$ & 0.0373 & 0.0309 & 0.0113 & 0.0139 & 0.0226 & 0.0183 \\
\hline $\operatorname{lag} 6$ & 0.0070 & 0.0079 & -0.0397 & -0.0427 & -0.0156 & -0.0116 \\
\hline $\operatorname{lag} 7$ & 0.0183 & 0.0145 & 0.0533 & 0.0536 & 0.0085 & 0.0066 \\
\hline $\operatorname{lag} 8$ & -0.0176 & -0.0172 & -0.0435 & -0.0326 & -0.0069 & -0.0091 \\
\hline $\operatorname{lag} 9$ & 0.0323 & 0.0314 & -0.0107 & -0.0097 & 0.0285 & 0.0207 \\
\hline $\operatorname{lag} 10$ & -0.0466 & -0.0443 & -0.0451 & -0.0518 & -0.0306 & -0.0335 \\
\hline $\operatorname{lag} 11$ & -0.0067 & -0.0110 & 0.0740 & 0.0772 & -0.0147 & -0.0193 \\
\hline $\operatorname{lag} 12$ & -0.0117 & -0.0092 & 0.0275 & 0.0211 & 0.0173 & 0.0148 \\
\hline
\end{tabular}

N otes: $f_{t}$ and $s_{t}$ denote the log-level of the futures price and the log-level of the spot price respectively. PACF is the partial autocorrelation function, and its standard deviation can be approximated by the square root of the reciprocal of the number of observations, $\mathrm{T}=643$, hence being equal to about 0:00155. 
Table 3. J ohansen maximum likelihood cointegration procedure

Panel a) S\&P 500

$L R$ tests based on the maximum eigenvalue of the stochastic matrix

\begin{tabular}{llll}
\hline \hline $\mathrm{H}_{0}$ & $\mathrm{H}_{1}$ & $\mathrm{LR}$ & $95 \% \mathrm{CV}$ \\
\hline $\mathrm{r}=0$ & $\mathrm{r}=1$ & 56.60 & 14.06 \\
$r \cdot 1$ & $\mathrm{r}=2$ & 0.27 & 3.84 \\
\hline \hline
\end{tabular}

LR tests based on the trace of the stochastic matrix

\begin{tabular}{llll}
\hline \hline $\mathrm{H}_{0}$ & $\mathrm{H}_{1}$ & $\mathrm{LR}$ & $95 \% \mathrm{CV}$ \\
\hline $\mathrm{r}=0$ & $\mathrm{r}=1$ & 56.87 & 15.41 \\
$r \cdot 1$ & $\mathrm{r}=2$ & 0.27 & 3.84 \\
\hline \hline
\end{tabular}

Panel b) NIKKEI 225

$L R$ tests based on the maximum eigenvalue of the stochastic matrix

\begin{tabular}{llll}
\hline \hline $\mathrm{H}_{0}$ & $\mathrm{H}_{1}$ & $\mathrm{LR}$ & $95 \% \mathrm{CV}$ \\
\hline $\mathrm{r}=0$ & $\mathrm{r}=1$ & 84.44 & 14.06 \\
$r \cdot 1$ & $\mathrm{r}=2$ & 2.083 & 3.84 \\
\hline \hline
\end{tabular}

LR tests based on the trace of the st ochastic matrix

\begin{tabular}{llll}
\hline \hline $\mathrm{H}_{0}$ & $\mathrm{H}_{1}$ & $\mathrm{LR}$ & $95 \% \mathrm{CV}$ \\
\hline $\mathrm{r}=0$ & $\mathrm{r}, 1$ & 86.52 & 15.41 \\
$r \cdot 1$ & $\mathrm{r}=2$ & 2.083 & 3.84 \\
\hline \hline
\end{tabular}

(continued ...) 
(... Table 3 continued)

Panel C: FT SE 100

$L R$ tests based on the maximum eigenvalue of the stochastic matrix

\begin{tabular}{llll}
\hline \hline $\mathrm{H}_{0}$ & $\mathrm{H}_{1}$ & $\mathrm{LR}$ & $95 \% \mathrm{CV}$ \\
\hline $\mathrm{r}=0$ & $\mathrm{r}=1$ & 60.47 & 14.06 \\
$r \cdot 1$ & $\mathrm{r}=2$ & 0.02 & 3.84 \\
\hline \hline
\end{tabular}

LR tests based on the trace of the stochastic matrix

\begin{tabular}{llll}
\hline \hline $\mathrm{H}_{0}$ & $\mathrm{H}_{1}$ & $\mathrm{LR}$ & $95 \% \mathrm{CV}$ \\
\hline $\mathrm{r}=0$ & $\mathrm{r}, 1$ & 60.49 & 15.41 \\
$r \cdot 1$ & $\mathrm{r}=2$ & 0.02 & 3.84 \\
\hline \hline
\end{tabular}

N otes: The model being tested for cointegration is equation (9). $H_{0}$ and $H_{1}$ denote the null hypothesis and the alternative hypothesis respectively; $r$ denotes the number of cointegrating vectors and the $95 \%$ critical values reported in the last column aretaken from Osterwald-L enum (1992). 
Table 4. Linearity tests on the residuals from linear VECM S

Panel a) Linear VECM (13) (complete separation)

RESET tests

\begin{tabular}{|c|c|c|c|}
\hline & $S \& P 500$ & NIKKEI 225 & FTSE 100 \\
\hline futu & 0 & 0 & $5.90 \pm 10^{i 2}$ \\
\hline spot & $1.64 \pm 10^{\circ} 2$ & $1.29 f 10^{i} 3$ & $7.17 f 10^{i} 2$ \\
\hline
\end{tabular}

BDS tests

\begin{tabular}{|c|c|c|c|c|c|c|}
\hline & \multicolumn{3}{|c|}{$v=2$} & \multicolumn{3}{|c|}{$v=3$} \\
\hline & $\&=0: 5$ & $\varepsilon=1: 0$ & $\&=1: 5$ & $\varepsilon=0: 5$ & $\&=1: 0$ & $\&=1: 5$ \\
\hline \multicolumn{7}{|c|}{$S \& P 500$} \\
\hline $\begin{array}{l}\text { futures equation } \\
\text { spot equation }\end{array}$ & $\begin{array}{l}3.02 \pm 10^{i} 6 \\
1.18 \pm 10^{i} 5\end{array}$ & $\begin{array}{l}8.85 \pm 10^{i} 7 \\
6.80 \pm 10^{i} 7\end{array}$ & $\begin{array}{l}4.01 \pm 10^{i} 7 \\
2.66 £ 10^{i} 6\end{array}$ & $\begin{array}{l}2.10 f 10^{i} 7 \\
2.05 f 10^{i} 7\end{array}$ & $\begin{array}{l}1.18 f 10^{i} 7 \\
4.38 f 10^{i} 8\end{array}$ & $\begin{array}{l}3.51 f 10^{i} 8 \\
5.79 f 10^{i} 8\end{array}$ \\
\hline \multicolumn{7}{|c|}{ NIKKEI 225} \\
\hline $\begin{array}{l}\text { futures equation } \\
\text { spot equation }\end{array}$ & $\begin{array}{l}3.13 f 10^{i} 8 \\
2.40 f 10^{i} 9\end{array}$ & $\begin{array}{l}2.13 f 10^{i} 7 \\
4.37 f 10^{i} 8\end{array}$ & $\begin{array}{l}1.10 £ 10^{i} 6 \\
3.86 \pm 10^{i} 7\end{array}$ & $\begin{array}{l}2.77 f 10^{i} 14 \\
2.44 f 10^{i} 15\end{array}$ & $\begin{array}{l}4.79 f 10^{i} 10 \\
6.32 f 10^{i} 11\end{array}$ & $\begin{array}{l}1.32 f 10^{i} 8 \\
8.42 f 10^{i}\end{array}$ \\
\hline \multicolumn{7}{|c|}{ FTSE 100} \\
\hline $\begin{array}{l}\text { futures equation } \\
\text { spot equation }\end{array}$ & $\begin{array}{l}2.77 \pm 10 i 1 \\
4.30 £ 10 i 1\end{array}$ & $\begin{array}{l}2.77 f 10 i 1 \\
3.15 f 10 i 1\end{array}$ & $\begin{array}{l}2.96 \pm 10 \mathrm{i} 1 \\
3.21 f 10 \mathrm{i} 1\end{array}$ & $\begin{array}{l}5.79 f 10 \mathrm{i}^{2} \\
7.14 \mathrm{f} 10 \mathrm{i}^{2}\end{array}$ & $\begin{array}{l}4.86 f 10 i^{2} \\
4.47 f 10{ }^{2} 2\end{array}$ & $\begin{array}{l}3.34 f 10 \mathrm{i}^{2} \\
1.43 \mathrm{f} 10 \mathrm{i} 2\end{array}$ \\
\hline
\end{tabular}

(continued ...) 
(... Table 4 continued)

Panel b) Linear VECM (14) (type-B separation)

RESET tests

\begin{tabular}{|c|c|c|c|}
\hline & S\&P 500 & NIKKEI 225 & 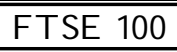 \\
\hline fut & $7.60 \pm 10^{i} 4$ & $1.08 \pm 10^{i} 3$ & 0 \\
\hline $\mathrm{spc}$ & $1.00 \pm 10^{i} 5$ & $9.47 \pm 10^{i} 3$ & 0 \\
\hline
\end{tabular}

BDS tests

\begin{tabular}{|c|c|c|c|c|c|c|}
\hline & \multicolumn{3}{|c|}{$v=2$} & \multicolumn{3}{|c|}{$v=3$} \\
\hline & $\&=0.5$ & $\&=1: 0$ & $\&=1: 5$ & $\varepsilon=0: 5$ & $\&=1: 0$ & $\&=1: 5$ \\
\hline \multicolumn{7}{|c|}{$S \& P 500$} \\
\hline futures equation & $5.52 £ 10^{i} 7$ & $7.42 £ 10^{i} 7$ & $1.37 f 10^{i} 6$ & $7.42 f 10^{i} 9$ & $4.31 f 10^{i} 8$ & $9.06 £ 10 ; 8$ \\
\hline spot equation & $2.09 \pm 10^{i} 6$ & $2.53 \pm 100^{7}$ & $4.37 f 10^{i} 6$ & $1.59 f 10^{i} 8$ & $5.14 f 10^{i} 9$ & $8.16 f 10^{i} 8$ \\
\hline \multicolumn{7}{|c|}{ NIKKEI 225} \\
\hline futures equation & $1.20 f 10^{i} 5$ & $1.99 f 10$ i 5 & $3.15 f 10^{i} 5$ & $1.97 £ 10^{i} 9$ & $1.71 £ 10^{i} 7$ & $1.02 f 10^{i} 6$ \\
\hline spot equation & $5.36 £ 10^{i} 7$ & $6.17 \pm 10^{i} 6$ & $2.42 f 10^{i} 5$ & $2.93 f 10^{i} 10$ & $5.38 £ 10^{i} 8$ & $1.27 f 10$ \\
\hline \multicolumn{7}{|c|}{ FTSE 100} \\
\hline futures & $2.36 £ 10 \mathrm{i} 1$ & $3.68 f 10 \mathrm{i} 1$ & $2.77 f 10 \mathrm{i} 1$ & $3.79 f 10 i 2$ & $3.56 £ 10 ; 2$ & $1.14 \mathrm{f} 10 \mathrm{i}^{2}$ \\
\hline spot equation & $3.12 f 10 \mathrm{i} 1$ & $3.08 f 10 \mathrm{i} 1$ & $4.34 f 10 \mathrm{i}^{1}$ & $2.52 f 10 \mathrm{i}^{2}$ & $1.55 f 10 \mathrm{i}^{2}$ & $9.48 f 10 i^{3}$ \\
\hline
\end{tabular}

Notes: Panel a): Under the RESET test statistic, the alternative model involves a higher-order polynomial to represent a di ßer ent functional form; in the present context we computed the RESET test considering an alternative model with a quadratic and a cubic term under the null of linearity. The RESET test statistic is distributed as $\hat{A}^{2}(q)$ with $q$ equal to the number of higher-order terms in the alternative model. $P$ anel $b)$ : The BD S test statistic tests the null hypothesis that a series is iid against the alternative of a realization from an unspeci ${ }^{-}$ed nonlinear process (see footnote 15 ). The critical values, from the normal distribution, are 1:960 and 2:576 at the -ve percent and one percent nominal levels of signi $i^{-}$cance respectively. For both RESET tests and BDS tests, we report $p$-values; $p$-values lower than equal to zero at the 8th decimal point are reported as 0 . 
Table 5. Likelihood ratio tests

\begin{tabular}{|c|c|c|}
\hline & $\overline{L L R 1}$ & $\overline{L L R} 2$ \\
\hline Bivariate VECM for S\&P 500 & $\begin{array}{c}239.49 \\
9: 70 £ 10^{i} 44^{a}\end{array}$ & 1 \\
\hline Bivariate VECM for NIK KEI 225 & 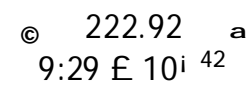 & | \\
\hline Bivariate VECM for FTSE 100 & 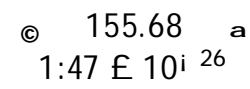 & | \\
\hline Multivariate VECM (all indices) & $\begin{array}{l}\text { (c) } 1765.95 \\
7: 11 \pm 10^{\mathrm{i}} 110^{\mathrm{a}}\end{array}$ & (c) $\begin{array}{r}1658.32 \\
9: 38 \pm 10^{\circ} 95^{a}\end{array}$ \\
\hline
\end{tabular}

N otes: Figures in braces denote $p_{i}$ values. LR1 is the likelihood ratio test where the model is not identi ${ }^{-}$ed under the null due to the existence of nuisance parameters. In this case it tests the null hypothesis of a linear VECM against the alternative hypothesis of an MSIH-VECM with two regimes. LR2 is the likelihood ratio test calculated to test the restrictions in (10). LR 2 is distributed as $\hat{A}^{2}(\mathrm{~g})$ where $\mathrm{g}$ is the number of restrictions imposed.

Table 6. In-sample performance: coe \pm cients of determination, $R^{2}$ and $\bar{R}^{2}$

\begin{tabular}{|c|c|c|c|c|}
\hline & VECM (13) & VECM (14) & "MSIH-VECM (15) & $\overline{\text { MSIH-VECM (16) }}$ \\
\hline \multicolumn{5}{|c|}{$R^{2}$} \\
\hline$S \& P 500 f_{t}$ & 0.038 & 0.045 & 0.103 & 0.660 \\
\hline$S \& P 500 \mathrm{st}_{\mathrm{t}}$ & 0.022 & 0.029 & 0.102 & 0.649 \\
\hline NIKKEI $225 \mathrm{f}_{\mathrm{t}}$ & 0.007 & 0.024 & 0.018 & 0.503 \\
\hline NIK KEI $225 \mathrm{st}_{\mathrm{t}}$ & 0.006 & 0.022 & 0.019 & 0.454 \\
\hline FTSE $100 \mathrm{f}_{\mathrm{t}}$ & 0.011 & 0.036 & 0.044 & 0.550 \\
\hline FTSE $100 \mathrm{~s}_{\mathrm{t}}$ & 0.004 & 0.032 & 0.034 & 0.553 \\
\hline \multicolumn{5}{|l|}{ 每 } \\
\hline$S \& P 500 f_{t}$ & 0.037 & 0.038 & 0.100 & 0.260 \\
\hline$S \& P 500 \mathrm{~s}_{\mathrm{t}}$ & 0.021 & 0.025 & 0.098 & 0.256 \\
\hline NIKKEI $225 \mathrm{f}_{\mathrm{t}}$ & 0.007 & 0.020 & 0.017 & 0.198 \\
\hline NIK KEI $225 \mathrm{St}_{\mathrm{t}}$ & 0.006 & 0.018 & 0.018 & 0.179 \\
\hline FTSE $100 \mathrm{f}_{\mathrm{t}}$ & 0.011 & 0.030 & 0.043 & 0.217 \\
\hline FTSE $100 \mathrm{~s}_{\mathrm{t}}$ & 0.004 & 0.028 & 0.033 & 0.218 \\
\hline
\end{tabular}

Notes: $R^{2}$ and $\bar{R}^{2}$ are the coe \pm cient of determination and the adjusted coe \pm cient of determination respectively. The adjusted coet cient of determination is calculated as K rolzig (1997, p. 133-4). 
Table 7. Out-of-sample performance: point forecasting

Panel a) $R^{2}$ out of sample, mean absolute error and mean square error

\begin{tabular}{|c|c|c|c|c|}
\hline \multicolumn{5}{|c|}{$\begin{array}{c}\text { VECM (14) MSIH-VECM (15) } \\
\text { S\&P } 500\end{array}$} \\
\hline $\begin{array}{l}R_{\text {out }}^{2} \\
M A E \\
M S E\end{array}$ & $\begin{array}{c}0.02297 \\
9.83 \pm 10^{i} 3 \\
1.48 f 10^{i} 4\end{array}$ & $\begin{array}{c}0.03263 \\
9.85 f 10^{\mathrm{i}} 3 \\
1.50 £ 10^{\mathrm{i}} 4\end{array}$ & $\begin{array}{c}0.03475 \\
9.93 £ 10{ }^{i} 3 \\
1.53 £ 100^{4}\end{array}$ & $\begin{array}{c}0.15624 \\
9.62 f 10^{\circ} 3 \\
1.47 f 10^{\circ}\end{array}$ \\
\hline \multicolumn{5}{|c|}{ NIKKEI 225} \\
\hline $\begin{array}{l}R_{\text {out }}^{2} \\
M A E \\
M S E\end{array}$ & $\begin{array}{c}0.00688 \\
9.01 f 10^{i} 3 \\
1.17 f 10^{i} 4\end{array}$ & $\begin{array}{c}0.02867 \\
8.63 £ 10^{\mathrm{i}} 3 \\
1.07 £ 10^{\mathrm{i}} 4\end{array}$ & $\begin{array}{c}0.01077 \\
9.06 £ 10^{\circ} 3 \\
1.17 \pm 10^{i} 4\end{array}$ & $\begin{array}{c}0.19867 \\
9.21 \notin 10^{i} 3 \\
1.36 \notin 10^{i}\end{array}$ \\
\hline \multicolumn{5}{|c|}{ FTSE 100} \\
\hline $\begin{array}{l}\mathrm{R}_{\text {out }}^{2} \\
\mathrm{MAE} \\
\mathrm{MSE}\end{array}$ & $\begin{array}{c}0.00744 \\
7.99 f 10^{i} 3 \\
1.01 f 10^{i} 4\end{array}$ & $\begin{array}{c}0.03102 \\
7.70 f 10^{i} 3 \\
1.01 f 10{ }^{\circ} 4\end{array}$ & $\begin{array}{c}0.01165 \\
7.92 £ 10^{i} 3 \\
9.95 £ 10^{i} 5\end{array}$ & $\begin{array}{c}0.15827 \\
8.27 f 10^{\circ} 3 \\
1.07 f 10^{i} 4\end{array}$ \\
\hline
\end{tabular}

Panel b) Diebold-Mariano test

\begin{tabular}{lccc}
\hline \hline & $\frac{M S I H i V E C M(16)}{V E C M(13)}$ & $\frac{M S I H \text { VECM (16) }}{V E C M(14)}$ & $\frac{M S I H i V E C M(16)}{M S I H i V E C M(15)}$ \\
& & $S \& P 500$ & 0.48856 \\
MAE & 0.65134 & 0.61190 & 0.81491 \\
MSE & 0.74570 & 0.94730 & \\
& & NIKKEI 225 & 0.75752 \\
& & 0.33101 & 0.14197 \\
MAE & 0.66788 & 0.07743 & \\
& 0.15895 & FTSE 100 & 0.24916 \\
\hline MAE & 0.35726 & 0.09708 & 0.29550 \\
MSE & 0.37056 & 0.46857 & \\
\hline \hline
\end{tabular}

N otes: $P$ anel a): $R_{\text {out }}^{2}$ is the out-of-sample coe \pm cient of determination calculated as $\mathrm{R}_{\text {out }}^{2}=3 / 2=3 / 2$ where $3 / 2$ is the variance of the forecast obtained by model $\mathrm{i}$ and $3 / 2$ is the variance of the forecasted variable. MAE and MSE denote the mean absolute error and the mean square error respectively. Panel b): Figures are $p_{i}$ values from executing Diebold-M ariano (1995) test statistics for the null hypothesis that the two competing models $i$ and $j$ have equal point forecast accuracy; $\frac{\operatorname{model} i}{\operatorname{model} j}$ denotes that the two competing models being tested under the Diebold-Mariano statistic are model $i$ and model $j$. The spectral density of the loss di ßerential function at frequency zero $\mathrm{D}_{(0)}$ ) is estimated using the optimal truncation lag according to the A R (1) A ndrews's (1991) rule. The $\mathrm{p}_{i}$ values were calculated by bootstrap methods using a variant of the procedure suggested by Kilian (1999). 
Table 8. A bsolute di ßerences in moments

\begin{tabular}{|c|c|c|c|c|}
\hline \multicolumn{5}{|c|}{ S\&P 500} \\
\hline$\overline{1}_{1}$ & $1.12 f 10^{i 4}$ & $3.73 f 10^{\mathrm{i}} 4$ & $5.49 f 10^{i} 4$ & $1.03 f 10^{i} 4$ \\
\hline${ }_{2}^{1}$ & $1.38 f 10^{i} 4$ & $1.36 f 10^{i} 4$ & $1.36 £ 10 i^{4}$ & $1.19 f 10 ; 4$ \\
\hline${ }_{3}^{1}$ & $1.28 f 10^{i} 7$ & $1.27 f 10^{\mathrm{i}} 7$ & $1.26 £ 10 ; 7$ & $2.46 \pm 10^{i 7}$ \\
\hline${ }^{1} 4$ & $5.41 f 10^{i} 8$ & $5.40 £ 10^{i} 4$ & $5.40 £ 10 ; 8$ & $5.13 \pm 10^{i} 8$ \\
\hline \multicolumn{5}{|c|}{ NIKKEI 225} \\
\hline${ }_{1}^{1}$ & $2.83 \pm 10^{i 3}$ & $7.81 f 10^{i} 4$ & $2.88 \pm 10^{i 3}$ & $3.79 \pm 10^{\mathrm{i}^{3}}$ \\
\hline${ }^{1}$ & $1.08 f 10^{i} 4$ & $1.05 f 10^{i} 4$ & $1.07 £ 10^{i} 4$ & $8.73 \pm 10^{i} 5$ \\
\hline${ }_{3}^{1}$ & $2.53 f 10^{\mathrm{i} 7}$ & $2.55 f 10^{i} 7$ & $2.51 £ 10^{i} 7$ & $3.05 f 10^{i} 7$ \\
\hline${ }_{4}^{1}$ & $2.90 f 10^{i} 8$ & $2.90 f 10^{i} 8$ & $2.90 £ 10 ; 8$ & $2.72 f 10^{i} 8$ \\
\hline \multicolumn{5}{|c|}{ FTSE 100} \\
\hline${ }_{1}^{1}$ & $9.98 \pm 10^{i} 4$ & $1.05 f 10^{i 3}$ & $1.04 \pm 10^{i 3}$ & $4.50 f 10^{i 5}$ \\
\hline${ }^{1} \frac{1}{2}$ & $9.99 f 10^{i} 5$ & $9.75 f 10^{i} 5$ & $9.95 £ 10$ i 5 & $9.48 \pm 10^{i} 5$ \\
\hline${ }_{3}^{1}$ & $6.31 f 10^{i} 7$ & $6.33 f 10^{i} 7$ & $6.29 \pm 10 ; 7$ & $6.25 \pm 10^{i} 7$ \\
\hline${ }_{4}^{1}$ & $3.30 f 10^{i} 8$ & $3.30 f 10^{i} 8$ & $3.30 \pm 10{ }^{i} 8$ & $3.27 f 10^{i} 8$ \\
\hline
\end{tabular}

N otes: ${ }^{1}{ }_{1},{ }_{2}{ }_{2}{ }^{1}{ }_{3},{ }_{3}{ }_{3}$ are the absolute di ${ }^{\circ}$ erences between the means, variances, third and fourth central moments of the estimated (linear and nonlinear) VECM models and the corresponding moments of actual data.

Table 9. Out-of-sample performance: density forecasting

\begin{tabular}{|c|c|c|}
\hline$\frac{\mathrm{MSIH} \text { i VECM (16) }}{V E C M(13)}$ & $\begin{array}{c}\text { MSIH } H_{i} V E C M(16) \\
V E C M(14) \\
S \& P 500\end{array}$ & 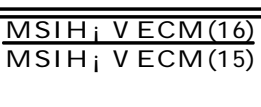 \\
\hline $\begin{array}{l}f_{1: 43 f 10^{i} 6^{x}} \\
\end{array}$ & $\begin{array}{l}f_{1: 09 f 10 ; 5^{x}}^{4.3966} \\
\text { NIKKEI } 225\end{array}$ & $f_{6: 47 \pm 10^{i} 5^{x}}$ \\
\hline$f_{2: 10 f 10^{i} 8^{a x}}^{5.6034}$ & $\begin{array}{l}f^{2.0967}{ }^{a x} \\
\text { FT SE } 100\end{array}$ & 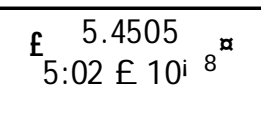 \\
\hline $\begin{array}{c}4.7508 \\
2: 02 f 10^{i} 6^{a}\end{array}$ & $f_{6: 89 f 10^{i} 2^{\not \alpha}}$ & $\begin{array}{l}f^{4} \quad 4.2595 \\
2: 04 £ 10^{i} 5^{\alpha a}\end{array}$ \\
\hline
\end{tabular}

N otes: Figur es denote the '-test statistic for equal density forecast accuracy and corresponding $\mathrm{p}_{\mathrm{i}}$ values (in brackets), constructed as described in the text. The null hypothesis is that the two competing models $\mathrm{i}$ and $\mathrm{j}$ have equal density forecast accuracy; $\frac{\text { mode } \mathrm{i}}{\mathrm{j}} \mathrm{de}$ notes that the two competing models being tested under the '-test statistic are model i and model $j$. The integrated square di ®erences were calculated using the Gaussian kernel estimator and setting the smoothing parameter according to the Silverman's (1986) rule. The number of bootstrap replications $B=100$ : T he test is distributed as $N(0 ; 1)$ under the null (see Appendix B). 


\section{A The transition matrix of the MSIH-VECM}

In Section 2.2 we mentioned that the underlying regime-generating process is assumed to be an ergodic $M$ arkov chain with a ${ }^{-}$nite number of states $z_{t} 2 \mathrm{f} 1 ;:: ; ; M g$ governed by the transition probabilities $p_{j}=\operatorname{Pr}\left(z_{t}=j j z_{t_{i} 1}=i\right)$, and ${ }_{j=1}^{M} p_{i j}=18 i ; j 2 f 1 ;:: ; ; M g$. If we move from the perspective of a single system of variables (i.e. futures and spot returns in a single stock market) towards a model where several systems of variables are jointly considered (i.e. non-separation is explicitly considered, M SIH-VECM (16)), we need to specify the joint process governing the transitional dynamics of the whole system. De ne $\mathrm{z}_{\mathrm{t}}^{\mathrm{SP}}, \mathrm{z}_{\mathrm{t}}^{\mathrm{NK}}$ and $\mathrm{z}_{\mathrm{t}}^{\mathrm{FT}}$ the unobserved variable governing the transitional dynamics of the $S \& P$ 500, NIK KEI 255 and FTSE 100 indices respectively, and assume $M=2$.

In order to achieve greater ${ }^{\circ}$ exibility, at the cost of a high computational burden, we make no assumption about the relationship between the shifts occurring in the three markets examined, so that $z_{t}^{\dot{A}}$ would be an outcome of a Markov chain with transition probabilities $p_{i j}^{\grave{A}}$ where $z_{t}^{\grave{A}}$ is independent of $z_{t}^{\tilde{A}}$ with $\tilde{A} \Theta \dot{A}$ for any $t$. In order to analyze the whole dynamics of the MSIH-VECM (16) we construct the following latent variable

$$
\begin{aligned}
& »_{t}=1 \text { if } z_{t}^{S P}=1, z_{t}^{N K}=1 \text { and } z_{t}^{F T}=1 \\
& »_{t}=2 \text { if } z_{t}^{S P}=2, z_{t}^{N K}=1 \text { and } z_{t}^{F \top}=1 \\
& »_{t}=3 \text { if } z_{t}^{S P}=1, z_{t}^{N K}=2 \text { and } z_{t}^{F \top}=1 \\
& \gg_{t}=4 \text { if } z_{t}^{S P}=2, z_{t}^{N K}=2 \text { and } z_{t}^{F \top}=1 \\
& »_{t}=5 \text { if } z_{t}^{S P}=1, z_{t}^{N K}=1 \text { and } z_{t}^{F \top}=2 \\
& »_{t}=6 \text { if } z_{t}^{S P}=2, z_{t}^{N K}=1 \text { and } z_{t}^{F \top}=2 \\
& »_{t}=7 \text { if } z_{t}^{S P}=1, z_{t}^{N K}=2 \text { and } z_{t}^{F \top}=2 \\
& »_{t}=8 \text { if } z_{t}^{S P}=2, z_{t}^{N K}=2 \text { and } z_{t}^{F T}=2 \text { : }
\end{aligned}
$$

Under this formalization the latent variable "t governing the transitional dynamics of the whole system M SIH-VECM (16) follows an 8-state Markov chain whose transition probabilities can be easily calculated from the probabilities of the chain governing $z_{t}^{S P}, z_{t}^{N ~}$ and $\mathrm{z}_{\mathrm{t}}^{\mathrm{F}}$. For example:

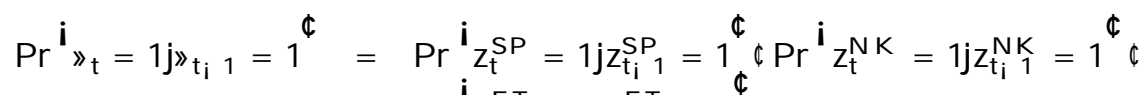

$$
\begin{aligned}
& \operatorname{Pr}^{i} z_{t}^{F T}=1 j z_{t_{i}}^{F T}=1^{\phi} \\
& =p_{11}^{S P} p_{11}^{N K} p_{11}^{F \top} \text { : }
\end{aligned}
$$

\section{B The '-test for equal density forecast accuracy}

This appendix $b$ rie $^{\circ} \mathrm{y}$ outlines the derivation of the '-test statistic for the null hypothesis of equal density forecast accuracy. Consider two series of forecasts, say $f t_{1}+g_{t=1}^{T_{1}}$ and $f y_{2 t} g_{t=1}^{T_{2}}$, obtained from two competing models, say $M_{1}$ and $M_{2}$. Let $f(y)$ be the probability density function of the variable $y_{t}$ over the period $t=1 ;:: ; T$, and $g_{1}(y)$ and $g_{2}(y)$ be the 
probability density functions of the two forecast series $f t_{1 t} g_{t=1}^{T_{1}}$ and $f y_{2 t} g_{t=1}^{T_{2}}$ respectivel ${ }^{30}$ A ssume that $f(y), g_{1}(y)$ and $g_{2}(y)$ are associated with distribution functions $F, G_{1}$ and $\mathrm{G}_{2}$ respectively, and $\mathrm{F}, \mathrm{G}_{1}$ and $\mathrm{G}_{2}$ are absolutely continuous with respect to the Lesbegue measure in $\mathrm{R}^{\mathrm{p}}$.

We are interested in testing the null hypothesis of equidistance of the probability densities $g_{1}(y)$ and $g_{2}(y)$ from $f(y)$, that is

$$
\mathrm{H}_{0}: \operatorname{dist}\left[\mathrm{f}(\mathrm{y}) ; g_{1}(\mathrm{y})\right]=\operatorname{dist}\left[\mathrm{f}(\mathrm{y}) ; g_{2}(\mathrm{y})\right] ;
$$

where the operator dist denotes a generic measure of distance:

A common measure of global closeness between two functions is the integrated square di ßerence (ISD) (e.g. see Pagan and Ullah, 1999):

$$
I S D=\left[A ́(x) i^{\circ}(x)\right]^{2} d x ;
$$

where $A(\phi)$ and ${ }^{\circ}(\phi$ denote probability density functions; ISD, 0 , and ISD $=0$ only if $A^{\prime}(x)={ }^{\circ}(x)$. U sing (B2) we can rewrite the null hypothesis $H_{0}$ in (B 1) as follows:

$$
\begin{aligned}
H_{0} & : \quad\left[f(y) ; g_{1}(y)\right]^{2} d y={ }^{Z}\left[f(y) ; g_{2}(y)\right]^{2} d y \\
& : \quad I S D_{1} ; \quad I S D_{2}=0:
\end{aligned}
$$

Under (B3) the null hypothesis of equal density forecast accuracy of model $M_{1}$ and $M_{2}$ is written as the null hypothesis of equality of two integrated square di Ber ences or, equivalently, as the null hypothesis that the di ßerence between two integrated square di ßerences is zero.

$W$ ith observations $f y_{t} g_{t=1}^{\top}, f y_{1 t} g_{t=1}^{\top}$ and $f b_{2 t} g_{t=1}^{\top}$ we can consistently estimate the unknown functions $f(y), g_{1}(y)$ and $g_{2}(y)$ using kernel estimation to obtain:

$$
\begin{aligned}
& H(y)=\frac{1}{T h}_{i=1}^{X^{\top}} k^{\mu} \frac{y_{i} i y^{q}}{h} \\
& \phi_{1}(y)=\frac{1}{T h}_{i=1}^{X^{\top}} K^{\mu} \frac{y_{1 i} i y^{\text {? }}}{h} \\
& g_{2}(y)=\frac{1}{T h}_{i=1}^{X^{\top}} K^{\mu} \frac{y_{2 i} i y^{q}}{h}
\end{aligned}
$$

where $K(\Phi$ is the kernel function and $h$ is the smoothing parameter. Using (B 4)-(B6) we can then obtain a consistent estimate of the integrated square di ßerences ISD 1 and ISD 2 . $D e^{-} n e d=\left|\$ D_{1} i \quad\right| \$ D_{2}$ as the estimated relative distance between the probability density functions. In order to test for the statistical signi ${ }^{-}$cance of $d$, the next step is to calculate a con ${ }^{-}$dence interval for $\mathrm{d}$.

\footnotetext{
${ }^{30}$ For simplicity and for clarity of exposition, throughout thi s section, we consider the casewhere $T_{1}=T_{2}=$ $T$, although the results derived below can be easily extended to the more general case where $T_{1} \in T_{2} \in T$.
} 


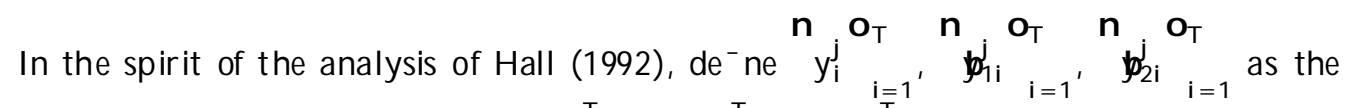
$j_{i}$ th resample of the original data $f y_{t} g_{t=1}^{\top}, f g_{1 t} g_{t=1}^{\top}, f b_{2 t} g_{t=1}^{\top}$, drawn randomly with replacement. From these resamples it is possible to obtain consistent bootstrap estimates of

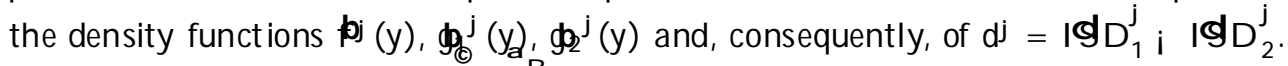

Consider a sample path $\mathrm{dj}_{\mathrm{j}=1}$, where $\mathrm{B}$ is the number of bootstrap replications. Under general conditions ${ }^{31}$, we have:

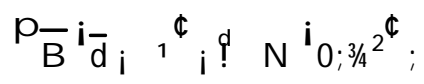

where

$$
\bar{d}=\frac{1}{B}_{j=1}^{X B} d^{j}=\frac{1}{B}{ }_{j=1}^{X{ }^{3}}\left|\omega D_{1}^{j} i\right| \$ D_{2}^{j}
$$

is the average di ßerence of the estimated distances over B bootstrap replications. Because in large samples the aver age di ßerence $\bar{d}$ is approximately normally distributed with mean 1 and variance $3 / 4=B$, the large sample statistic for testing the null hypothesis that models $M_{1}$ and $M_{2}$ have equal density forecast accuracy is:

$$
=\frac{\bar{d}}{\frac{B A 2}{B}} i ? \text { ? } N(0 ; 1) \text {; }
$$

where $3 z_{4}^{2}$ is a consist ent estimate of $3 / 4.32$

A s mentioned in the main text, this test statistic may be seen as the analogue of the test of Diebold and Mariano (1995) in the context of density forecasting. Sarno and Valente (2001), using M onte $C$ arlo methods designed to investigate the size and power properties of this test statistic, show that the '-test has satisfactory empirical size and power properties in " nite sample in a variety of circumstances with a number of boostrap replications equal to 100 or so.

${ }^{31}$ See Kendall and Stuart (1976, Ch. 11).

32On the consistency of the bootstrap estimates of $3 / 4$ in this context see Hall (1992) and Mammen (1992). 


\section{References}

Andrews, D.W.K. (1991), \ Heteroskedasticity and A utocorrelation Consistent Covariance Matrix Estimation," Econometrica, 59, 817-858.

A ng, A . and B ekaert, G. (2001), I Stock Return P redictability: Is it There?," National Bureau of E conomic Research W orking Paper 8207.

Brock, W .A., Dechert, W .D. and Scheinkman, J . (1991), Nonlinear Dynamics, Chaos, and Instability. Cambridge, Mass.: M IT Press.

Cecchetti, S.G., Lam P. and Mark, N.C. (1990), \M ean Reversion in Equilibrium A sset Prices," American Economic Review, 80, 398-418.

Cecchetti, S.G., Lam P. and M ark, N.C. (2000), \A sset Pricing with Distorted B eliefs: A re E quity Returns Too Good to be True?," A merican Economic Review, 90, 787-805.

Clements, M .P. and Hendry, D.F . ( 1998), Forecasting E conomic T ime Series, C ambridge: Cambridge University P ress.

Davies, R.B. ( 1977), \Hypothesis Testing when a Nuisance Parameter is P resent only under the Alternative," Biometrika, 64, 247-254.

Dempster, A.P., Laird, N.M . and R ubin, D.B. (1977), \M aximum Likelihood Estimation from Incomplete Data Via the EM A Igorithm," J ournal of the Royal Statistical Society, 39, Series $B, 1-38$.

Diebold, F.X., Gunther, T .A. and Tay, A.S. (1998), IE valuating Density Forecasts with A pplications to Financial Risk M anagement," I nternational Economic Review, 39, 863-883.

Diebold, F.X., Hahn, J . and Tay, A.S. (1999), I Multivariate Density Forecast Evaluation and Calibration in $\mathrm{F}$ inancial $\mathrm{R}$ isk $\mathrm{M}$ anagement: High-Frequency Returns on Foreign Exchange," Review of Economics and Statistics, 81, 661-673.

Diebold, F.X. and Mariano, R.S. (1995), I Comparing P redictive A ccuracy," J ournal of Business and E conomic Statistics, 13, 253-263.

Diebold, F.X., Gunther, T.A. and Tay, A.S. (1998), \E valuating Density Forecasts with A pplications to Financial Risk M anagement," I nternational E conomic Review, 39, 863-883.

Dwyer, G .P. J r., Locke, P.R. and Yu, W . (1996), IIndex A rbitrage and Nonlinear D ynamics between the S\&P 500 Futures and $C$ ash," Review of $F$ inancial Studies, 9, 301-32.

Engle, R.F. and Granger, C.W .J . (1987), IC o-integration and Error Correction Representation, Estimation and Testing," Econometrica, 55, 251-276.

Engle, R.F. and Susmel, R. (1994), \ Hourly Volatility Spillovers between International Equity $M$ arkets," J ournal of International M oney and Finance, 13, 3-25.

Eun, C.S. and Shin, S. (1989), \I International Transmission of Stock M arket M ovements," J ournal of Financial and Quantitative Analysis, 24, 241-256.

Franses, P.H. and van Dijk, D. (2000), Non-linear Time Series Models in Empirical Finance, Cambridge and New Y ork: Cambridge University Press.

Gallant A.R (1987), Nonlinear Statistical Models, New York, NY : J . W iley.

Gallant, A.R., Rossi, P.E., and Tauchen, G., (1993), INonlinear Dynamic Structures," Econometrica 61, 871-907.

Gao, A.H. and Wang, G.H.K., (1999), \M odeling Nonlinear Dynamics of Daily Futures Price Changes," J ournal of Futures M arkets, 19, 325-351.

Garcia, R. (1998), \A symptotic Null Distribution of the Likelihood R atio Test in Markov Switching M odels," Internati onal E conomic Review, 39, 763-788.

Goetzmann, W.N., Li, L. and Rouwenhorst, K.G. (2001), I Long-term Global Market Correlations," National Bureau of E conomic R esearch Working Paper No. 8612. 
Granger, C.W .J . (1986), ID evelopments in the Study of Cointegrated Variables," Oxford Bulletin of E conomics and Statistics, 48, 213-228.

Granger, C.W .I and Pesaran, M.H. (1999), $\backslash$ A Decision Theoretic A pproach to Forecast Evaluation," in Chan, W.S., Lin, W.K. and Tong, H. (eds.), Statistics and Finance: An Interface, L ondon: Imperial College Press.

Granger, C.W .J . and Swanson, N. ( 1996), \Future Developments in the Study of Cointegrated Variables," Oxford Bulletin of E conomics and Statistics, 58, 537-53.

Granger, C.W.J ., and Haldrup, N. (1997), ISeparation in Cointegrated Systems and Persistent-Transitory Decompositions," Oxford Bulletin of Economics and Statistics, 59, 449-63.

Granger, C.W.I. and Pesaran, M.H., (1999), \A Decision Theoret ic A pproach to Forecast Evaluation," in Chan, W.S., Lin, W.K. and Tong, H. (eds.), Statistics and Finance: An Interface, L ondon: Imperial College Press.

Hall, P. (1992), IE eect of Bias Estimation on Coverage Accuracy of B ootstrap Con dence Intervals for a Probability Density" A nnals of Statistics, 20, 675-694.

Hamilton, J.D. (1988), IRational Expectations Econometric Analysis of Changes in R egime. An Investigation of the Term Structure of Interest R ates," J ournal of Economics Dynamics and Control, 12, 385-423.

Hamilton, J.D. (1989), \A New Approach to the Economic A nalysis of Nonstationary T ime Series and the B usiness Cycle," Econometrica, 57, 357-384.

Hamilton, J.D. (1993), I Estimation, Inference and Forecasting of T ime Series Subject to Changes in Regime," in Maddala, G.S., Rao, C.R. and Vinod, H.D. (eds.), Handbook of E conometrics, Vol. 4, Elsevier, A msterdam.

Hamilton, J.D., and Lin, G. (1996), IStock Market Volatility and the Business Cycle," J ournal of Applied E conometrics, 11, 573-93.

Hamilton, J.D. and Susmel, R. (1994), \A utoregressive Conditional Heteroskedasticity and Changes in Regime," J ournal of Econometrics, 64, 307-333.

Hansen, B .E. (1992), IT he Likelihood R atio Test under Nonstandard Conditions: Testing the Markov Switching Model of GNP," J ournal of Applied Econometrics, 7, S, 61-82.

Hansen, B.E. (1996), \Erratum: The Likelihood Ratio Test under Nonstandard Conditions: Testing the Markov Switching M odel of GNP," J ournal of A pplied E conometrics, 11, 195-198.

J ohansen, S. (1988), I Statistical A nalysis of Cointegrating Vectors," J ournal of Economic Dynamics and Control, 12, 231-254.

J ohansen, S. (1991), \Estimation and Hypothesis Testing of Cointegrating Vectors in Gaussian Vector Autoregressive Models," E conometrica, 59, 1551-1580.

J ohansen, S. (1995), Likelihood-based Inference in Cointegrated VAR Models. Oxford: Oxford U niversity P ress.

Karatzas, I. and Shreve, S.E. (1998), M ethods of M athematical Finance, NY: Springer.

Karlsen, H.A . (1990), A Class of N on-Linear Time Series M odels, University of Bergen, un published $P$ h. D. dissertation.

Karolyi, G.A and Stulz, R.M. (1996), I Why Do Markets Move Together? An Investigation of U.S.-J apan Stock Return Comovements," J ournal of Finance 51, 951-86.

Kendall, M.G. and Stuart, A. (1976), The Advanced Theory of Statistics, Vol. 1, 4th edition, London: Charles $\mathrm{Gri} \pm \mathrm{n}$ and $\mathrm{C} 0$.

Kilian, L. (1999), \Exchange R ates and M onetary Fundamentals: What Do We Learn from L ong-Horizon Regressions?," J ournal of A pplied Econometrics, 14, 491-510. 
Kilian, L. and Taylor, M.P. (2001), IW hy Is It so Di \pm cult to B eat the Random Walk Forecast of Exchange Rates?" , C entre for E conomic Policy Research Discussion Paper No. 3024.

Kim, C.-J . and Nelson, C.R . (1999), State-Space Models with Regime Switching, Cambridge, Mass. and London, UK: MIT Press.

Konishi, T. and Granger, C.W .J . (1993), ISeparation in Cointegrated Systems," University of California San Diego mimeo.

K oop, G., P esaran, H. M . and P otter, S. (1996), II mpul se R esponse A nalysis in Nonlinear Multivariate M odels," J ournal of Econometrics, 74.

Koutmos, G. and Booth, G.G. (1995), \A symmetric Volatility Transmission in International Stock Markets," J ournal of I nternational M oney and Finance, 14, 747-762.

K rolzig, H.-M . (1997), M arkov-Switching Vector Autoregressions, N ew Y ork, NY : Springer.

K rolzig, H.-M . (1999), IStatistical Analysis of Cointegrated VAR Processes with Marko-

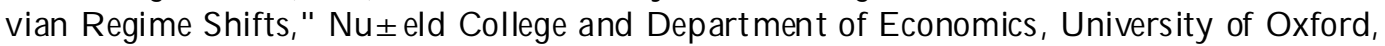
mimeo.

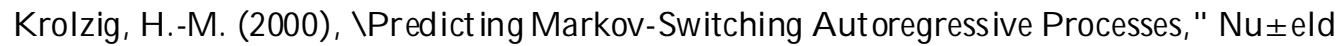
College and Department of E conomics, University of Oxford, mimeo.

LeB aron, B. (1992), \Forecast Improvements Using a Volatility Index," J ournal of Applied E conometrics, 7, 137-49.

Lee, B.-S. (1998), \Permanent, T emporary, and Non-fundamental Components of Stock Prices," J ournal of Financial and Quantitative A nalysis, 33, 1-32.

Lee, B.-S. and J eon, B.N. (1995), IC ommon Stochastic Trends and Predictability of International Stock Prices," J ournal of the J apanese and International Economi es, 9, 24577.

Mammen, E. (1992), When D oes B ootstrap Work: A symptotic Results and Simulations, Lecture Notes in Statistics, 77, Berlin: Springer-Verlag.

M cC racken, M.W . (2000), \ R obust Out-of-Sample Inference," J ournal of E conometrics, 99, 195-223.

Miller, M.H., Muthuswamy, J . and Whaley, R.E. (1994), I M ean Reversion of Standard \& Poor's 500 Index Basis Changes: A rbitrage-Induced or Statistical Illusion?," J ournal of Finance, 49, 479-513.

Neely, C.J . and Weller, P. (2000), \Predictability in International A sset Returns: A R eexamination," J ournal of Financial and Quantitative A nalysis, 35, 601-620.

Newey, W.K. and West, K.D. (1987), \A Simple, Positive Semi-de- nite, Heteroskedasticity and Autocorrelation Consistent Covariance Matrix," E conometrica, 55, 3, 703-708.

Pagan, A. and Ullah, A. (1999), Nonparametric E conometrics, Cambridge, New York and $\mathrm{M}$ el bourne: $\mathrm{C}$ ambridge University Press.

Pesaran, M.H. and Skouras, S. (2001), IDecision-based Methods for Forecast Evaluation," in Clements, M.P. and Hendry, D.F. (eds.), A Companion to Economic Forecasting, Oxford: B lackwell, forthcoming.

Osterwald-Lenum, M . (1992), \A N ote with Quantiles of the A sympt otic Distribution of the M aximum Likelihood Cointegration R ank Test Statistics," Oxford Bulletin of Economics and Statistics, 54, 461-472.

Pan, M.S. and Hsueh, L.P. (1998), I Transmission of Stock R eturns and Volatility B etween the US and J apan: Evidence from the Stock Index Futures Market," Asia-Paci ${ }^{-} \mathrm{C}$ Financial Markets, 5, 211-225.

Ramsey, J .B. (1969), I Tests for Speci ${ }^{-}$cation Errors in Classical Least-Squares Regression A nalysis," J ournal of the Royal Statistical A nalysis, Series B, 31, 350-371. 
R amchand, L., and Susmel, R. ( 1998a), I Volatility and Cross Correlation across Major Stock Markets," J ournal of Empirical Finance, 5, 397-416.

R amchand, L., and Susmel, R. (1998b), IVariances and Covariances of International Stock Returns: The International Capital A sset Pricing Model Revisited," J ournal of International Financial Markets, Institutions and Money, 8, 39-57.

R yden, T ., T er ̈̈svirta, T . and A sbrink, S. ( 1998), I Stylized Facts of Daily R eturn Series and the Hidden Markov Model," J ournal of A pplied E conometrics, 13, 217-44.

Saikkonen, P. (1992), \Estimation and Testing of Cointegrated Systems by an Autoregressive A pproximation," Econometric Theory, 8, 1-27.

Saikkonen, P. and Luukkonen, R. (1997), I Testing Cointegration in In ${ }^{-}$nite Order Vector A utoregressive Processes," J ournal of E conometrics, 81, 93-126.

Sarno, L. and Valente, G. (2001), IC omparing the A ccuracy of Density Forecasts from Competing Models," University of Warwick, mimeo.

Silverman, B.W . (1986), Density Estimation for Statistics and Data Analysis, N ew York: Chapman and Hall.

Susmel, R. (1999), I Switching Volatility in International Equity M arkets," U niversity of Houston mimeo.

Tay, A.S. and Wallis, K.F. (2000), I Density Forecasting: A Survey," J ournal of Forecasting, 19, 235-254.

T immermann, A . (2000), \ Density Forecasting in Economics and Finance: Editorial," J ournal of Forecasting, 19, pp. 231-234.

West, K.D. (1996), \A symptotic Inference about Predictive A bility," E conometrica, 64, 1067-1084.

West, K.D. and M cC racken, M. W . (1998), \ R egression-based Tests of Predictive A bility," International Economic Review, 39, 817-840.

Yadav, P.K., Pope, P.F . and Paudyal, K . (1994), IThreshold A utor egressive M odeling in F inance: The Price Di ßerences of Equivalent A ssets," M athematical Finance, 4, 205-221. 